\title{
A survey of finite element analysis of temperature and thermal stress fields in powder bed fusion Additive Manufacturing
}

Zhibo Luo, Mechanical Engineering Department, McGill University

Yaoyao Zhao, Mechanical Engineering Department, McGill University

\section{Abstract}

This survey aims to provide a review on the application of finite element method to optimize process parameters and improve the mechanical performance of a part fabricated by powderbed-fusion Additive Manufacturing process. The state-of-the-art finite element models in the simulation of powder bed fusion process are reviewed. Numerical modeling methodologies of the laser beam melting or electron beam melting process at the macro-level are summarized in detail. Specifically, the importance of pre-processing of the part model, process parameters, mesh scheme, and temperature-dependent material properties are clarified. Simulation techniques used to reduce the computational cost are also discussed. Then the existing finite element models in the simulation of powder-bed fusion processes are reviewed and discussed. Simulation results are classified based on the characteristics of the melt pool and the printed part. Then the simulation results are validated by the experiment results. Finally, the significance of finite element method in the connection of other Additive Manufacturing issues such as material design, in-process monitoring and control, and process optimization are explained. The drawbacks of existing finite element models are summarized. And potential new methods to optimize process parameters of PBF process are proposed.

Keywords: Additive manufacturing, selective laser melting, electron beam melting, simulation, finite element model, powder bed fusion

\section{Introduction}

Powder bed fusion process is one of the seven Additive Manufacturing (AM) processes defined by ASTM in 2012 [1]. According to the ASTM technical committee, the seven AM processes are defined as powder bed fusion (PBF), directed energy deposition, binder jetting, material jetting, sheet lamination process, material extrusion, and Vat photopolymerization. Among these AM processes, the previous five types are able to process metal materials [2]. Readers who are interested in these AM techniques could find detail descriptions in these references [3, 4]. Compared with other AM processes, PBF mainly utilizes energy source with high density such as laser beam or electron beam to selectively melt the metal powder with the desired shape on the powder bed and join the material layer by layer. Based on the difference of heat source, PBF can be further divided into Selective Laser Melting/Sintering (SLM/SLS) which utilizes laser beam as the heat source [5] and Electron Beam Melting (EBM) which utilizes electron beam as the heat source [6]. The initial SLS process is developed by the University of Texas and the company DTM Corporation [7]. The initial EBM process is developed by the Chalmers University of Technology in Sweden and is commercialized by Acram AB company [3]. Compared to the laser beam, the electron beam has higher energy density and is more efficient, and thus EBM manufacturing process is more efficient. Another difference between EBM and SLM is the resulting microstructure. In general, the laser beam scanning tracks are usually easy to distinguish, whereas the electron beam scanning tracks are not easy to identify. This difference can be attributed to 
the low energy density and low efficiency of the laser beam, which result in non-melting or partially melting particles among subsequent layers. In addition, a more moderate thermal stress of EBM processed part compared to the SLM processed part can be attributed to the preheating process of the powder bed in EBM process.

PBF process has numerous merits over traditional manufacturing processes [8] such as machining, forging, and casting. First, it can build a part with complex geometrical features such as lattice structures, which cannot be manufactured via conventional manufacturing methods. Second, it is cost effective for high complexity part in small batches. Third, it has the ability to build an assembled product, which results in reduced assembly need. Due to the ability to fabricate a part with complex geometries and nearly full density [9], PBF process has been widely used in automobile, aerospace, biomedical, and energy industry [10-14]. Many types of metal powders can be used in the PBF process. Stainless steel, aluminum, Ti6Al4V, nickel alloys, are materials of high interest in these industries [15-18]. Lightweight and durable components filled with lattice structure are more desired in the aerospace industry; customized bio-implants can only be fabricated through AM techniques [19].

However, several process deficiencies such as balling effect $[20,21]$, deteriorated surface finish [22], part shrinkage [23], pores and micro-cracks [24], residual stress-induced defects including warping and distortion [25], have been discovered in PBF process and remain as unsolved issues. Most of these defects are induced by the significant temperature gradient during the heating and cooling cycles. Especially for a part with overhang features, rapid heating and cooling processes will result in the deformation of overhang features, and support structures are needed to build it successfully $[26,27]$. On the other hand, support structures are not easy to remove and place restrictions on the design freedom for complex parts. Significant efforts have been spent to restrict the number of supports and minimize deformation of PBF processed parts. As experimental method typically takes vast amount of time and cost and cannot delineate the variation of temperature fields or thermal stress fields with respect to the time, numerical analysis of temperature and thermal stress fields development in a part with overhang feature is needed to analyze the relations between process parameters and mechanical performance of final part. Numerical modeling of temperature distribution, thermal stress and deformation occurred in the PBF process is similar to that of multi-pass welding process [28], which has been developed and modeled for four decades. However, compared to the modeling of the multi-pass welding process, modeling of PBF process introduces significant amount of computational work due to several coupled and complicated physical phenomena such as the irradiation of laser beam on the powder bed, heat transfer, fluid dynamics in the melt pool, evaporation and chemical reactions within the melt pool. Though there have existed many numerical methods to model the history of temperature fields and thermal stress fields, most of them are not easy to implement due to lack of sufficient information. In addition, only limited amount of research has studied the finite element analysis of PBF process [29-32]. The existing numerical models and reviews are not easy to understand for newcomers in the field of AM.

This review attempts to provide an overview of the finite element analysis (FEA) of PBF process for newcomers in this field who want to optimize the process parameters to achieve a better mechanical performance of final printed parts. In section 2, the detailed process of numerical modeling methodologies such as heat source, material properties, boundary conditions, and meshing strategy will be provided. In section 3, the existing finite element models (FEMs) will be reviewed. After that, in section 4, simulation results of the reviewed FEMs will be presented in the form of melt pool characters, temperature fields, and thermal stress/distortion fields. Then, 
experimental validation of the numerical results will be discussed in section 5 . Finally, the conclusions and some prospects will be summarized.

\section{Numerical modeling methodology}

The general flow chart for the modeling of temperature and thermal stress fields is shown in Figure 1. The major steps in the FE formulation and analysis of a typical problem include preprocessing, processing (thermal analysis and mechanical analysis), and post-processing. Next, the main procedures and techniques used in this figure will be explained in detail.

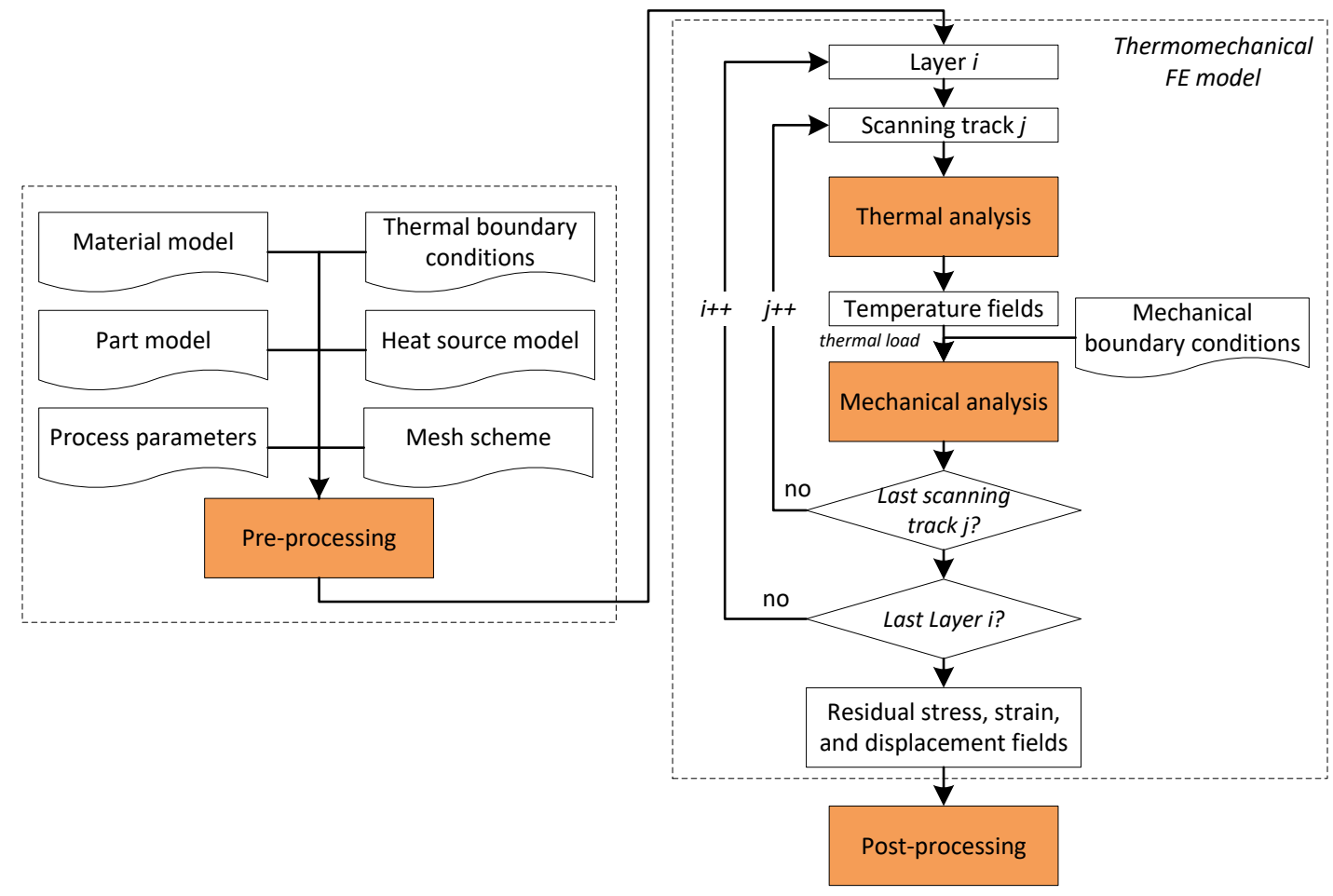

Figure 1. Flowchart of thermo-mechanical FE model

\subsection{Pre-processing}

\subsubsection{Part geometry}

Geometric model of a part defines the domain for the generation of finite element (FE) mesh and the subsequent FE analysis. The basic idea of the FE mesh is to view a given domain as an assemblage of simple finite elements such as triangular element and rectangular element in 2D or tetrahedral elements and hexahedral element in 3D [33]. Due to a large number of cells when meshing a part and hundreds of scan tracks for a layer with complex geometry, great computational costs are needed. Therefore, most of the 3D FE models [34-37] and 2D FE models [38-40] simulate the temperature and thermal stress evolutions with a simple geometry. The dimension of deposited part varies from several millimeters [41] to several centimeters [42]. However, even for a scanning domain with $6 \times 6 \mathrm{~mm}$ square, the simulation time for thermal and mechanical analysis could take 92 hours [43]. Therefore, the dimension of the part and substrate is the first thing needs to be considered carefully before the simulation process.

\subsubsection{Process parameters for PBF simulation}


The primary purpose of FE model for PBF process is to investigate the relationship between different process parameters and the (mechanical and geometrical) quality of final printed part. Unlike conventional manufacturing methods whose process parameters have been studied and optimized extensively in the past, the optimization of process parameters for PBF process is started somewhat recently. Usually, the process parameters for PBF process are optimized by experiment method $[44,45]$, which is time-consuming with a high cost. The evolution of temperature gradient and thermal stress within the part are closely correlated with scanning speed, scanning pattern, laser power, spot size, etc. [46]. Table 1 lists the necessary process parameters used in the finite element simulation. These parameters need to be specified before the FE analysis. The laser or electron power is supposed to be a Gaussian distribution with certain spot size $[36,45]$. For each layer, the heat source moves along the scanning vectors defined by the scanning pattern with certain scanning speed. The distance between two adjacent and parallel scanning vectors is the hatching space, which guarantees the fully melting or re-melting of each scanning track.

Table 1. Necessary process parameters for the simulation of PBF process

\begin{tabular}{|c|c|}
\hline Process parameters & Unit or notes \\
\hline Power of heat source & Watt \\
\hline Type of heat source & Gaussian distribution \\
\hline Scanning speed, $\mathrm{V}$ & Zigzag pattern \\
\hline Scanning pattern & $\mathrm{X}, \mathrm{Y}, \mathrm{Z}$ axis \\
\hline Scanning direction & Second \\
\hline Printing time for each layer & um \\
\hline Hatch spacing & um \\
\hline Spot size & um \\
\hline Layer thickness & Celsius/Kelvin \\
\hline Ambient temperature & $<1$ \\
\hline Efficient &
\end{tabular}

Many works, either through experiment or simulation, have been done to optimize these process parameters to either maximize strength or minimize residual stress and deformation of the end part. For example, it has been reported that powder bed temperature under pulsed wave mode laser is $30 \%$ lower than powder bed temperature under continuous wave mode laser [47]. A relatively low laser power results in increased voids and about $50 \%$ decrease in the material strength for stainless steel 316L [48], while high laser power increases the warping trend for overhanging surface [49]. A relatively lower scanning speed will improve the surface quality of a single layer while higher scanning speed will improve the surface quality of multi-layers [50]. Residual stress increases with the decrease of layer thickness [51]. Hardness and density of end part decrease with the increase of layer thickness while porosity increase with the increase of layer thickness [52]. Scanning strategy includes scanning pattern, scanning vector length, scanning direction. These process parameters have been studied widely to control the residual stressinduced deformation of end part $[53,54]$. Traditional scanning pattern applies "S" pattern to deliver laser energy to the whole deposited layer which would lead to large distortion due to long scanning vectors and the stress accumulation from underlying layers. Altering the scanning pattern with shorter scanning vectors can significantly reduce distortion [9, 55-57] while more deposition passes and processing time are required to deposition one layer. 


\subsubsection{Material model}

An effective material model which considers the variation of properties during the cycle of heating and cooling processes is fundamental [20]. Since the temperature varies from tens of Celsius degrees to thousands of Celsius degrees during PBF processes, most of the physical properties change drastically. For example, powder bed density of Titanium alloy decreases slowly with the increase of temperature before the melting point and then decreases sharply after reaching the melting point. Powder bed density increases irreversibly with the rise of temperature from the solidus temperature to liquidus temperature [58]. Masubuchi [59] stated that temperature dependent material property is one of the most important factors in the analysis of thermal stresses. Therefore, to eliminate the simulation error induced by the mismatched physical properties at different temperatures, the corresponding thermal and mechanical properties should be defined accurately with the variation of the temperature. In addition, the properties and behaviors of particle metal are completely different from bulk metal [60,61]. Both powder and solid materials can be specified as temperature dependent [36, 43]. However, in a number of studies $[35,62,63]$, the material properties of the solid material have considered being constant in order to reduce the computational cost. As thermophysical properties mainly influence the interaction between the heat source and powder bed, next the temperature-dependent thermophysical properties will be discussed in detail in the following section. For the temperature-dependent mechanical properties, readers can find useful information in these papers [36, 43].

\section{Density}

Among these thermophysical properties, the density is the most important one as it can influence many other material properties such as thermal conductivity $[7,64]$ and laser absorptivity of powder material $[65,66]$. In the powder bed, the evolution of density can be described in terms of time and temperature [7] and the sintering rate determines the density change [67]. In addition, powder state, phase change, and pores ratio can also exert some influence on the powder bed density. The powder bed porosity directly reveals the powder bed density. The size distribution and morphology of metal particles would influence the neck formation between particles. Thus, the density of printed part is mainly controlled by the bonding force between layers and hatching lines and shrinkage [68].

According to the assumptions for the density of powder bed, the relative density of powder material can changes from $40 \%$ to $60 \%$ of the solid material [24]. Childs et al. [40] use the following differential equation to describe the rate of variation of the powder bed density,

$$
\frac{d \rho}{d t}=\left(\rho_{\text {solid }}-\rho\right) \cdot A \cdot \exp \left(-\frac{E}{R \cdot T}\right)
$$

Where $\rho_{\text {solid }}$ is the density of the solid material, $A$ is the sintering pre-exponential factor of the material, $E$ is the activation energy, $R$ is the universal gas constant, and $T$ is the temperature.

Using backward difference algorithm where $d \rho / d t=\left(\rho_{t+\Delta t}-\rho_{t}\right) /(\Delta t)$, substitution of this equation into equation (1), the rate of variation of the powder bed density can be written as [69],

$$
\rho_{t+\Delta t}=\frac{\rho_{t}+\Delta t \cdot \rho_{\text {solid }} \cdot A \cdot \exp \left(-\frac{E}{R \cdot T}\right)}{1+\Delta t \cdot A \cdot \exp \left(-\frac{E}{R \cdot T}\right)}
$$


Where $\rho_{t}$ is the density obtained from the previous time step.

Another simplified model assumes that the density of powder bed is a function of solid material which is arranged in a cubic array. Patil [63] and Antony [70] calculated the density of powder bed using the following equation [71],

$$
\rho_{\text {bed }}=\frac{\pi \cdot \rho_{\text {solid }}}{6}
$$

Where $\rho_{\text {solid }}$ is the solid material density with the assumption that all particles have the same size and spherical shape.

Considering the accuracy of simulation results, equation (2) is preferred when modeling the PBF process. However, the temperature-dependent character of the powder bed density increases the nonlinearity of the finite element system. On the other hand, equation (3) assumes a constant powder bed density, which will significantly decrease the computational burden while losing some accuracy.

\section{Thermal conductivity}

Thermal conduction is the most important heat transfer mechanism in PBF process. For example, the thermal conductivity of loose powder is significantly lower than that of solidified material because the connection between particles is extremely limited to a small contact area. The particle size and compactness of powder bed exert great influence on the conduction of heat in SLM $[65,66]$. Bugeda et al. [7] proved that the thermal conductivity of powder bed could be obtained from the density. Shiomi et al. [64] assumed that the thermal conductivity of powder bed could be expressed as the function of the relative density of powders or porosity and validated this through an experiment of copper powder. The effective thermal conductivity of powder bed is determined by the portion of gas and pores among the powder bed and increase tremendously when it is melted [72, 73]. Rombouts et al. [74] also claimed that the effective thermal conductivity of powder bed is more dependent on the diameter and the shape of the particle, the pore ratio, and the thermal conductivity of gas reside in the pore rather than the material itself. In summary, higher thermal conductivity will result in a lower temperature in the powder bed. In order to counteract the effect of higher thermal conductivity, the input laser energy should be increased [75]. The essential of all the above-listed factors is that the effective thermal conductivity of powder bed is depended on the neck between adjacent particles. The diameter of this neck controls the rate of heat transfer. A decreased neck size means low thermal conductivity and vice versa [76].

Usually, the thermal conductivity of the solid material is determined at different temperatures through experiments. Then the effective thermal conductivity of powder bed is defined according to the porosity of powder bed and thermal conductivity of gas resided in pores. Yagui et al. [77] derived the effective thermal conductivity of the packed powder bed by using the following equation [7]

$$
k_{e f f}=\frac{\rho_{r} \cdot k_{s}(T)}{1+\Phi \cdot k_{s}(T) / k_{g}}
$$

Where $\rho_{r}$ is the relative density of powder bed, $k_{s}(T)$ is the solid thermal conductivity which is a function of temperature, $k_{g}$ is the surrounding gas thermal conductivity, and $\Phi$ is the empirical 
coefficient taken as equal to $0.02 \times 10^{2\left(0.7-\rho_{r}\right)}$. This equation enables the conductivity of powder bed as a function of local relative density.

Another model of effective thermal conductivity of powder bed is given by Childs et al. [40], which expressed as a function of heat conductivity of solid material $k_{S}(T)$ and porosity $\beta$,

$$
k_{e f f}=k_{s}(T) \cdot\left(1-0.2 \beta-1.73 \beta^{2}\right) \quad \text { eq. (5) }
$$

The heat conductivity of solid material $k_{S}(T)$ is given by Sun and Beaman [78] as a function of temperature $T$,

$$
k_{S}(T)=0.02504+0.0005 T \quad \text { eq. (6) }
$$

Apart from the above models, there are many other models that can be used to calculate the effective thermal conductivity of powder bed [34, 64, 79-81]. Among these models, equation (4) leads to a more accurate result as it combines the influence from the solid thermal conductivity, the gas thermal conductivity, and relative density of the powder bed, while equation (5) is easier to implement in the finite element system compared with equation (4).

\section{Specific heat}

Generally, the specific heat has a nonlinear relationship with the temperature change and phase transformation [75]. However, in order to reduce the complexity of the simulation model, many studies assume the specific heat of material at different temperature point is a linear or interpolation function of temperature [56, 82-84]. For example, Gaur et al. [85] applied the following equation to calculate the temperature-dependent specific heat capacity of polycarbonate,

$$
c_{p}=\left\{\begin{array}{ll}
-20.56+4.103 T, & T \leq T_{g} \\
935.34+2.284 T, & T>T_{g}
\end{array} \quad\right. \text { eq. (7) }
$$

Where $T_{g}$ presents the glass-transition temperature of polycarbonate.

\section{Latent heat}

The latent heat is defined as the heat released or absorbed during the exothermic or endothermic process of phase change. Thermal conductivity and specific heat capacity change greatly when the powder material undergoes the phase change from solid powder to liquid molten flow and finally solidified track [86]. The material temperature remains unchanging during the phase change process. The effect of latent heat on the temperature field is regarded by introducing an equivalent specific heat which improves greatly around the melting point [87]. Though the inclusion of latent heat will increase the accuracy of the simulation results, tons of computational effort is needed. The influence of latent heat has been included in many thermal models. For example, much research focuses on modeling of material phase change in AM process [88-90]. And other research has focused on the simulation of stress and distortion in the material which undergoes phase transformation [91].

The latent heat during the phase change can be calculated from the enthalpy $(H)$ of the material, which can be written as

$$
H(T)=\int \rho c(T) d T
$$


The curve of enthalpy with the variation of temperature can be classified into three sections: The temperature $(T)$ remains below the solidus temperature $\left(T_{S}\right)$, between solidus temperature and liquidus temperature $\left(T_{l}\right)$, and above the liquidus temperature. According to the specific heat and density at each temperature point and latent heat $(L)$, the enthalpy can be calculated as [92]

$$
H(T)=\left\{\begin{array}{cc}
\rho c_{s}\left(T_{s}-T\right) & T<T_{s} \\
\rho c_{s}\left(T_{l}-T_{s}\right) & T=T_{s} \\
\rho c_{s}\left(T_{l}-T_{s}\right)+\rho c^{*}\left(T-T_{s}\right) & T_{s}<T<T_{l} \\
\rho c_{s}\left(T_{l}-T_{s}\right)+\rho c^{*}\left(T_{l}-T_{s}\right) & T=T_{l} \\
\rho c_{s}\left(T_{l}-T_{s}\right)+\rho c^{*}\left(T_{l}-T_{s}\right)+\rho c_{l}\left(T-T_{l}\right) \quad T_{l}<T
\end{array}\right.
$$

Where $c^{*}=c_{\text {avg }}+L /\left(T_{l}-T_{s}\right), c_{\text {avg }}=\left(c_{s}+c_{l}\right) / 2$ and $L$ is the latent heat in unit mass.

\subsubsection{Mesh scheme}

The quality of the mesh will strongly influence the convergence of the numerical computation, the accuracy of computation results, and the computational efficiency. For most of the research, there are mainly two mesh schemes: the uniform mesh and the non-uniform mesh. Most of them use the non-uniform mesh scheme, which can refine the mesh in the region of interest. This popular technique used in AM simulation is called Adaptive Mesh Refinement (AMR) that can fill the region of interest with much denser mesh. According to whether the mesh is updated during the simulation, the AMR is further divided into static AMR and dynamic AMR. The mesh scheme of dynamic AMR can change the density of mesh depending on the value of thermal or strain gradients. From reviewing of existing research, it is only found the commercial software ANSYS Fluent [93], the open source finite element code Deal.II [94], the AM simulation tool Pan Computing [95] and 3DSIM [93] can apply dynamic and moving meshes. The classification of mesh scheme and their corresponding disadvantages and advantages are listed in Table 2. The examples of static adaptive mesh and dynamic adaptive mesh are shown in Figure 2. Usually, in the region of melt pool and its adjacent heat affected zone (HAZ), the element size should be at least half of the diameter of laser or electron beam which means the laser or electron spot needs to cover at least four elements. Therefore, the size of element size in the melt pool varies from $25 \mu \mathrm{m}$ to 75 $\mu m$ depending on the laser or electron beam [36, 70, 96]. For static AMR, Ren et al. [97] have established a finite element model which consists of two parts as shown in Figure 2.(a). The upper model with fine mesh is used to represent metal powder while the bottom model with coarse mesh is used to represent the substrate. Liu et al. [83] simulated the temperature field within the powder bed of SLS by utilizing 10-node tetrahedral element in ANSYS. In this work, a fine mesh is used in the scanning region and a coarse mesh is employed far away from the scanning area to save calculation time and improve efficiency. For dynamic AMR, Denlinger and Michaleris [98] dynamically mesh the finite element model by a software package named Pan Computing [95] (see Figure 2.(c)). 8-node hexahedral element is chosen and the mesh is refined and coarsened as the laser spot moves in and moves away from the deposition. Similarly, Dunbar [99] also employed this tool to simulate the stress and distortion of a simple cylindrical geometry within different scanning patterns. Another novel dynamic AMR has been formulated by Pal et al. [100]. This dynamic meshing strategy is applied specifically to AM process in a way that is tens of times faster than the more generic commercial packages. The adaptive meshes are generally moved with the energy source and refined near the sinks where high thermal or stress gradients are involved (see Figure 2.(b)). 


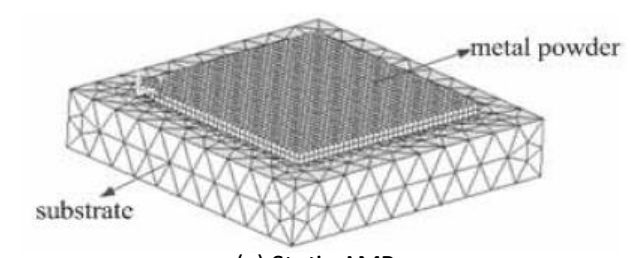

(a) Static AMR

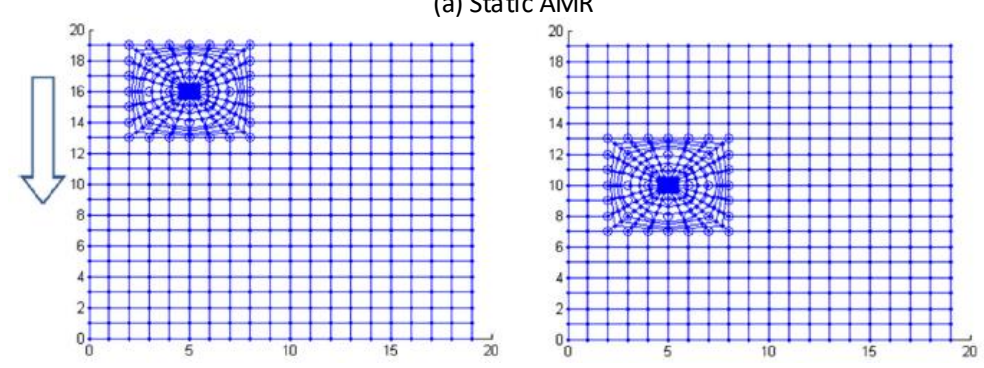

(b) Dynamic AMR (3DSIM)

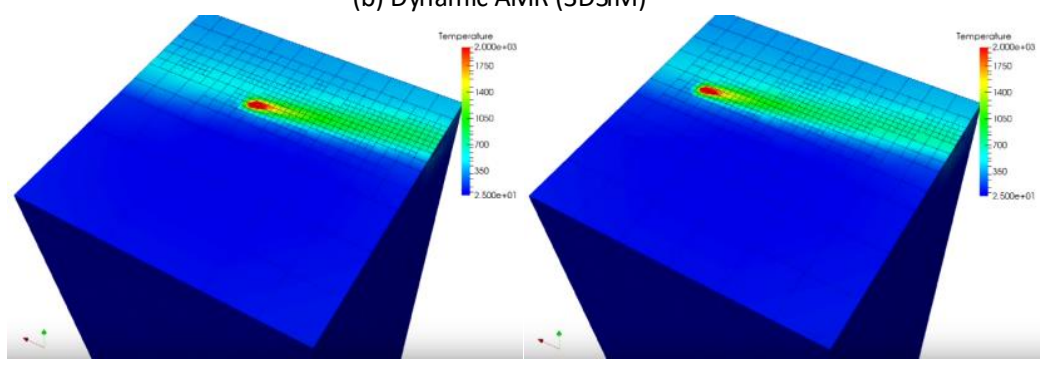

(c) Dynamic AMR (Pan Computing)

Figure 2. Examples of adaptive mesh [97, 98, 101]

Table 2. Mesh scheme in the modeling of AM

\begin{tabular}{|c|c|c|c|c|}
\hline & & Advantages & Disadvantages & References \\
\hline & orm & $\begin{array}{l}\text { Easy to implement; } \\
\text { Accurate results; }\end{array}$ & $\begin{array}{l}\text { Fine mesh is required; } \\
\text { Large number of elements; } \\
\text { High computational cost: }\end{array}$ & $\begin{array}{l}{[38,56} \\
63,102]\end{array}$ \\
\hline Non- & $\begin{array}{l}\text { Static } \\
\text { AMR }\end{array}$ & $\begin{array}{c}\text { Relatively low } \\
\text { computational cost and } \\
\text { high simulation accuracy; }\end{array}$ & $\begin{array}{l}\text { Mesh cannot change with melt pool; } \\
\text { Not suitable for multilayers; }\end{array}$ & $\begin{array}{c}{[35,36} \\
70,96,97 \\
103]\end{array}$ \\
\hline uniform & $\begin{array}{l}\text { Dynamic } \\
\text { AMR }\end{array}$ & $\begin{array}{l}\text { Low computational cost; } \\
\text { High simulation accuracy; } \\
\text { Suitable for multilayers; }\end{array}$ & $\begin{array}{l}\text { Not easy to implement; } \\
\text { Extra efforts are needed for data } \\
\text { transfer between old and new mesh; }\end{array}$ & $\begin{array}{c}{[93,95} \\
98,99 \\
104]\end{array}$ \\
\hline
\end{tabular}

\subsubsection{Heat source model}

The heat source model is critical to simulate the heat input in the PBF processes. Some studies just model the heat source as a temperature load [102, 105], while most common used heat source is the moving Gaussian heat source, which is a distributed heat source model. When the heat source is fixed, the distribution of heat flux can be described as [106]:

$$
q(r)=q_{\max } \exp \left(-k r^{2}\right) \quad \text { eq. (10) }
$$

Where $q_{\text {max }}$ is the maximum heat flux $\left(J / \mathrm{mm}^{2} \cdot s\right), k$ is concentration factor $\left(1 / \mathrm{mm}^{2}\right), r$ is the distance between a point and center of the heat source $(\mathrm{mm})$. 


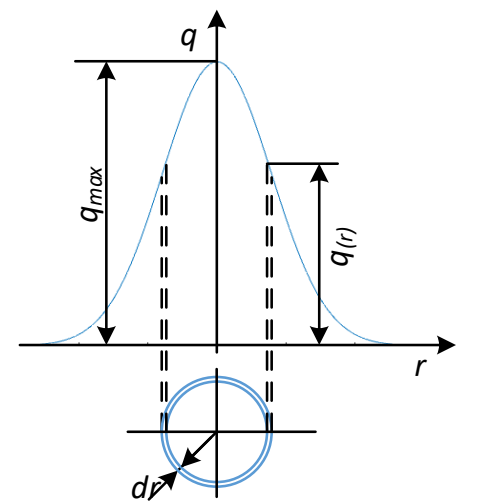

(a)

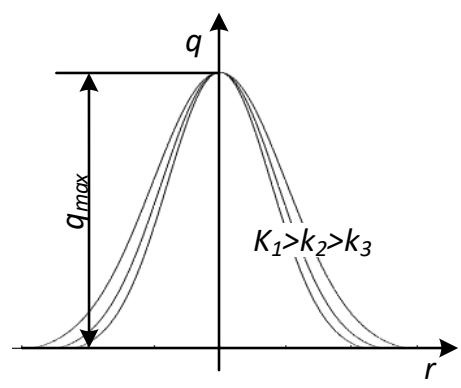

(b)

Figure 3. Distribution of Gaussian heat source

The maximum heat flux $q_{\max }$ can be obtained by integrating the heat flux over the whole area as shown in Figure 3. (a). Therefore, the total thermal heat equals to the effective power of heat source $Q$.

$$
Q=\int q(r) d A=\int_{0}^{\infty} q_{\max } \exp \left(-k r^{2}\right) \cdot 2 \pi r \cdot d r
$$

Solving this equation and get $q_{\max }=\frac{k}{\pi} Q$. Substitute $q_{\max }$ into equation (10) results in:

$$
q(r)=\frac{k Q}{\pi} \exp \left(-k r^{2}\right)
$$

When $95 \%$ of the thermal heat is absorbed within the radius of laser/electron spot $\omega$, then,

$$
95 \% \cdot Q=\int_{0}^{\omega} q(r) \cdot 2 \pi r \cdot d r=\int_{0}^{\omega} \frac{k Q}{\pi} \exp \left(-k r^{2}\right) \cdot 2 \pi r \cdot d r
$$

Solving this equation and get $k=\frac{3}{\omega^{2}}$ and finally,

$$
q(r)=\frac{3 Q}{\pi \omega^{2}} \exp \left(-\frac{3 r^{2}}{\omega^{2}}\right)
$$

Note that when $q_{\max }$ is fixed, with the increase of $k$, the heat source is more concentrated (see Figure 3. (b)). And it has been known that electron beam and laser beam have a relatively large value of $k$.

If the concentration factor is taken as $\frac{2}{\omega^{2}}$, it means $85 \%$ of heat source are absorbed within the radius of $\omega[36,97,107]$. Then, the common used Gaussian heat source in laser melting process

$$
q(r)=\frac{2 A P}{\pi \omega^{2}} \exp \left(-\frac{2 r^{2}}{\omega^{2}}\right)
$$

Where $A$ is the absorptivity of the powder material, $P$ the laser power, $\omega$ the maximum radius of laser spot, and $r$ the radial distance to the beam. 
When the heat source is moving along the scanning track, the powder ahead of the laser beam is continuously melted and solidified in the back of the laser beam. In this circumstance, the heat flux is a function of space and time, which is termed as Gaussian moving heat source. Based on the penetration depth of heat flux, the moving heat source can be modeled as area-related where heat flux is only applied on top of the surface; and volume-related where heat flux is generated within a small volume. Most studies have modeled the laser beam as an area-related heat source and electron beam as a volume-related heat source. Due to the difference of heat transfer mechanism, laser radiation can only penetrate the solid material up to several micrometers (about up to $20 \mu \mathrm{m}$ for nickel [102] and $65 \mu \mathrm{m}$ for titanium [108]), which is usually smaller than the element size. Therefore, the laser beam is usually considered as a surface heat source. Compared with the laser beam, the electron beam has much higher beam energy density without effects of reflectivity [109], which leads to a much larger penetration depth on powder bed [110]. Therefore, the electron beam is usually considered as a volumetric heat source. In the modeling of Gaussian moving heat source, scanning speed and time effects should be included in the fixed Gaussian heat source. For example, if it is assumed that the laser beam is scanning along $x$ direction on the top surface with uniform scan speed $v$, then equation (15) can be written as,

$$
\left.q(x, y, z, t)\right|_{z=\text { height of top surface }}=\frac{2 A P}{\pi \omega^{2}} \exp \left(-\frac{2\left[y^{2}+(x-v \cdot t)^{2}\right]}{\omega^{2}}\right)
$$

For the volume-related heat source, the heat flux can be applied in $x, y, z$ directions in the powder bed. Goldak et al. [106] proposed a double ellipsoidal heat source model, and the moving volumerelated heat source can be written as,

$$
q(x, y, z, t)=\frac{6 \sqrt{3} Q}{a b c \pi \sqrt{\pi}} \exp \left(-\frac{3\left(x-v_{x} t\right)^{2}}{a^{2}}-\frac{3\left(y-v_{y} t\right)^{2}}{b^{2}}-\frac{3 z^{2}}{c^{2}}\right)
$$

Where $a, b, c$ present the semi-axes of the ellipsoid in $x, y, z$ directions.

There are also many other different volume-related heat source models [45, 111]. The difference lies in the distribution of energy along the build orientation (z-direction). In reality, however, even a single layer material consists of hundreds of scanning tracks, substantial computational time and storage are needed to do the simulation. Recently, Rwin and Michaleris [112] proposed a linebased heat source model to reduce the computational cost. Simulation results from this research claimed that the computational time of line input heat source model could reduce to less than a tenth of the Goldak's moving heat source model. To summarize, the commonly used heat source models are classified and listed in Table 3. 
Table 3. Heat source models

\begin{tabular}{|c|c|c|c|c|}
\hline \multicolumn{2}{|c|}{ Heat source } & Equation & References & Profiles \\
\hline \multicolumn{2}{|c|}{ Temperature load } & $\begin{array}{c}\text { Temperature distribution obtained from } \\
\text { Gaussian heat source }\end{array}$ & {$[102,105]$} & - \\
\hline \multirow{3}{*}{$\begin{array}{l}\text { Gaussian } \\
\text { Moving } \\
\text { heat } \\
\text { source }\end{array}$} & $\begin{array}{l}\text { Area- } \\
\text { related }\end{array}$ & $q(r)=\frac{2 Q}{\pi \omega^{2}} \exp \left(\frac{-2\left[x^{2}+y^{2}\right]}{\omega^{2}}\right)$ & $\begin{array}{c}{[70,96} \\
107,113- \\
117]\end{array}$ & \\
\hline & \multirow[t]{2}{*}{$\begin{array}{l}\text { Volume- } \\
\text { related }\end{array}$} & $\begin{array}{c}q(r)=\frac{6 \sqrt{3} Q}{a b c \pi \sqrt{\pi}} \exp \left(-\frac{3 x^{2}}{a^{2}}-\frac{3 y^{2}}{b^{2}}\right. \\
\left.-\frac{3 z^{2}}{c^{2}}\right)\end{array}$ & $\begin{array}{c}{[28,98,99,} \\
118-120]\end{array}$ & \\
\hline & & $\begin{array}{l}q(r) \\
=\frac{A}{d} \exp \left(-\frac{z}{d}\right) \frac{2 Q}{\pi \omega^{2}} \exp \left(-\frac{2 x^{2}+2 y^{2}}{\omega^{2}}\right)\end{array}$ & $\begin{array}{c}{[43,121,} \\
122]\end{array}$ & - \\
\hline \multicolumn{2}{|c|}{$\begin{array}{l}\text { Gaussian line heat } \\
\text { source }\end{array}$} & $\begin{array}{l}q(r) \\
=\frac{3 P \eta}{\Delta t v a b \pi} \exp \left(-\frac{3 x^{2}}{a^{2}}\right. \\
\left.-\frac{3 y^{2}}{b^{2}}\right)\left.\operatorname{erf}\left(-\frac{\sqrt{3}(z+v t)}{c}\right)\right|_{t=t 0} ^{t 0+\Delta t}\end{array}$ & [112] & \\
\hline
\end{tabular}

\subsubsection{Boundary/Initial conditions}

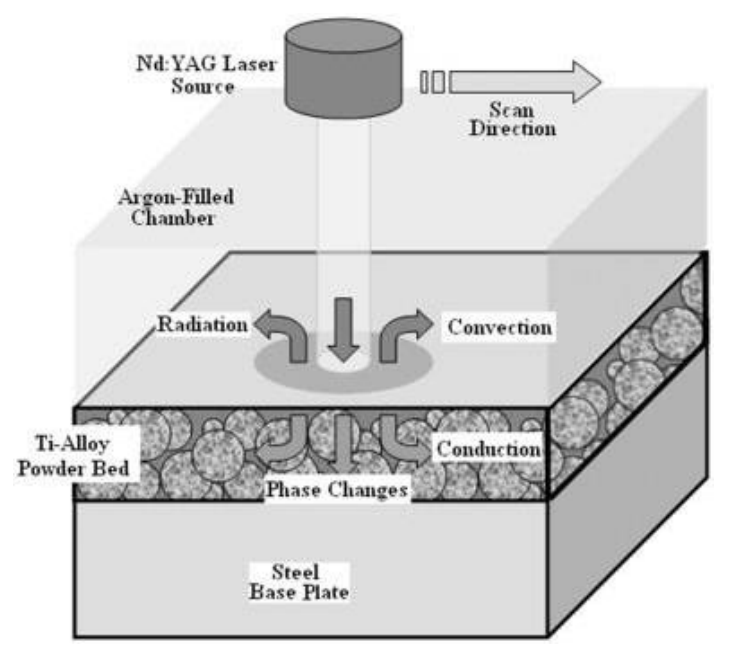

Figure 4. Heat transfer mechanism in laser melting process [72] 
Heat transfer mechanisms during the PBF process are presented in Figure 4. Boundary conditions mainly include heat convection, conduction and radiation and they are summarized in the follows. The part being built is exposed to the ambient atmosphere and surrounded by loose powders. The heat dissipated through the ambient atmosphere can be obtained by introducing the heat convection between the part and the ambient atmosphere. The heat dissipated from the bottom of the baseplate [123] and surface radiation [72, 116] are usually ignored for the reason of simplification. While other research $[43,117,124]$ include the impact of thermal radiation. Though these simplifications will increase the error of simulation results, the increased error is tiny because most of the heat is conducted through the powder bed and solidified layers [30].

In most of the existing research $[36,113,115,124,125]$ for the heat transfer problem, there are mainly two boundary conditions and an initial condition.

The initial condition with uniform/non-uniform temperature throughout the powder bed before the irradiation of laser beam can be written as,

$$
T(x, y, z, 0)=T_{0}(x, y, z) \text { for the whole domain at } t=0
$$

Where $T_{0}(x, y, z)$ is the ambient temperature at the initial time throughout the whole part and usually taken as $300 \mathrm{~K}$.

The first boundary condition specifies the heat transfer between the top and lateral surface and surrounding media.

$$
-\lambda \frac{\partial T}{\partial n}=h_{c}\left(T-T_{0}\right)+\epsilon_{\theta} \sigma\left(T^{4}-T_{0}^{4}\right) \text { on top and lateral surface for all } t
$$

Where $\lambda$ the thermal conductivity coefficient, $\frac{\partial T}{\partial n}$ the temperature gradient, $h_{c}$ the convection coefficient, $T_{0}$ the room temperature, $\epsilon_{\theta}$ the thermal radiation coefficient, and $\sigma$ the StefanBoltzmann constant.

Another boundary condition specifies that there is no heat exchange at the bottom surface of the powder bed, which means the bottom surface is heat insulated.

$$
-\left.\lambda \frac{\partial T}{\partial z}\right|_{z=\text { bottom surface }}=0 \text { on bottom surface for all } t \quad \text { eq. (20) }
$$

When the laser beam irradiates on the powder bed, most of the thermal heat is absorbed by the surface within the depth of $0.5 \mu \mathrm{m}$. Therefore, it can be considered as if the thermal heat is generated on the surface of powder and transferred to the surrounding powder or solidified material through thermal conduction.

\subsection{Thermal analysis}

The heat transfer process in laser heating is a very complicated problem. During the laser heating process, the energy source mainly comes from the radiation of laser beam, latent heat of phase change, and deformation heat. When the metal material is melted or solidified, latent heat will be released, which will influence the heat transfer process. In addition, the plastic deformation of the material will generate deformation heat. Usually, this portion of heat is very small compared to the other two heat sources. Therefore, it is not considered in the heat transfer process.

\section{Governing equations for heat transfer}


For uniformly and continuum isotropic-material, when material properties independent from the temperature, the heat transfer differential equation can be obtained through the principle of conservation of energy [36]:

$$
\frac{\partial T}{\partial t}=\frac{k}{c \rho}\left(\frac{\partial^{2} T}{\partial x^{2}}+\frac{\partial^{2} T}{\partial y^{2}}+\frac{\partial^{2} T}{\partial z^{2}}\right)+\frac{1}{c \rho} \frac{\partial Q_{v}}{\partial t}=a \nabla^{2} T+\frac{1}{c \rho} \frac{\partial Q_{v}}{\partial t}
$$

Where $k$ presents the thermal conductivity coefficient $(\mathrm{J} / \mathrm{mm} \cdot \mathrm{s} \cdot K), c$ the specific heat $(\mathrm{J} / \mathrm{g}$. $K), \rho$ the density $\left(\mathrm{g} / \mathrm{mm}^{3}\right), Q_{v}$ the consumed thermal energy of unit volume, $\frac{\partial Q_{v}}{\partial t}$ the internal heat intensity. $a=k / c \rho$ is the thermal diffusivity $\left(\mathrm{cm}^{2} / \mathrm{s}\right)$.

In reality, the powder material experiences solid-liquid-solid transformations which results in the absorption and release of latent heat. The latent heat usually cannot be ignored as it will greatly affect the temperature distribution. Therefore, the above equation (21) should incorporate the enthalpy change which can be obtained from equation (9) and then the heat conduction equation is written as

$$
\frac{\partial H}{\partial t}=k\left(\frac{\partial^{2} T}{\partial x^{2}}+\frac{\partial^{2} T}{\partial y^{2}}+\frac{\partial^{2} T}{\partial z^{2}}\right)+\frac{\partial Q_{v}}{\partial t}=k \nabla^{2} T+\frac{\partial Q_{v}}{\partial t}
$$

The thermal boundary condition and initial condition have been specified in section 2.1.6.

Both of the thermal conductivity and thermal diffusivity are temperature dependent, which means $k=k(T), a=a(T)$. In this circumstance, when the Galerkin method is implemented to represent this continuous problem as a discrete problem, the discretized weak form will be highly non-linear due to temperature dependent material properties.

\subsection{Mechanical analysis}

The finite element modeling of PBF process includes two different processes, which are the nonlinear transient thermal analysis and the quasi-static elastoplastic mechanical analysis. After the temperature field obtained from the above thermal analysis, a mechanical analysis is performed to approximate the thermal stress and deformation. The temperature field is now applied as the thermal load for the mechanical analysis. The thermal-mechanical analysis can be performed in coupled way or uncoupled way [30]. For the coupled analysis, the thermal expansion will influence the mechanical property, while the distorted geometry induced by the thermal expansion will influence the thermal property in turn. Therefore, the thermal and mechanical analyses should be performed concurrently for each time step [126]. For the uncoupled or weakly coupled analysis, the plastic deformation induced friction heat is much smaller compared to the thermal energy which means the interaction between temperature field and stress field are not tangled. Therefore, the thermal and mechanical analyses can be performed sequentially coupled [127]. In most of the existing cases $[43,124,128]$, the weakly coupled thermal-mechanical analysis method is preferred due to the less computational cost.

\section{Governing equations for thermal stress}

The non-linear mechanical analysis can be regarded as a quasi-static incremental analysis $[28,112$, 129]. The governing equation can be expressed as [87, 98]:

$$
\nabla \cdot \boldsymbol{\sigma}=0
$$

Where $\boldsymbol{\sigma}$ is the second-order stress tensor associated with the material behavior law. 
Considering the elastoplastic behavior of the material, strain and stress can be written as

$$
\boldsymbol{\sigma}=\boldsymbol{C} \boldsymbol{\epsilon}^{e} \quad \text { eq. (24) }
$$

Where $\boldsymbol{C}$ is the fourth order material stiffness tensor and $\boldsymbol{\epsilon}^{e}$ is the second-order elastic stain tensor. The total strain tensor $\boldsymbol{\epsilon}$ is consist of the elastic strain $\boldsymbol{\epsilon}^{e}$, the plastic strain $\boldsymbol{\epsilon}^{p}$, and the thermal strain $\boldsymbol{\epsilon}^{\text {th }}$ [112]:

$$
\boldsymbol{\epsilon}=\boldsymbol{\epsilon}^{e}+\boldsymbol{\epsilon}^{p}+\boldsymbol{\epsilon}^{t h}=\frac{1}{2}\left[\nabla \boldsymbol{u}+(\nabla \boldsymbol{u})^{T}\right] \quad \text { eq. }(25)
$$

And,

$$
\begin{aligned}
\boldsymbol{\epsilon}^{e} & =\frac{1+v}{E} \boldsymbol{\sigma}-\frac{v}{E} \operatorname{tr}(\boldsymbol{\sigma}) \mathrm{II} & & \text { eq. }(26) \\
\boldsymbol{\epsilon}^{p} & =g\left(\sigma_{Y}\right) & & \text { eq. }(27) \\
\boldsymbol{\epsilon}^{t h} & =\left[\begin{array}{lllll}
\epsilon^{t h} & \epsilon^{t h} \epsilon^{t h} & 0 & 0 & 0
\end{array}\right]^{\mathrm{T}} & & \text { eq. }(28) \\
\epsilon^{t h} & =\alpha\left(T-T_{0}\right) & &
\end{aligned}
$$

Where $E, v, \alpha, u$ are Young's modulus, Poisson's ratio, thermal expansion coefficient, and the displacement vector, respectively. The total strain $\epsilon \ll 1$ assumes that the deformation is small, which is the case in AM process. $g\left(\sigma_{Y}\right)$ is a function related to the yield strength $\left(\sigma_{Y}\right) . T$ and $T_{0}$ are the nodal temperature and the initial temperature, respectively.

For a pure plastic behavior with isotropic strain hardening, using the associative $J_{2}$ plasticity, the yield function $f$ is:

$$
f=\sigma_{m}-\left(\sigma_{y 0}+H \epsilon^{q}\right) \leq 0 \quad \text { eq. (29) }
$$

And,

$$
\begin{array}{ll}
\epsilon^{p}=\dot{\epsilon}^{q} \boldsymbol{a} & \text { eq. (30) } \\
\boldsymbol{a}=\left(\frac{\partial f}{\partial \sigma}\right)^{\mathrm{T}} & \text { eq. (31) }
\end{array}
$$

Where $\sigma_{m}, \sigma_{y 0}, H$, and $\epsilon^{q}$ is the Mises' stress, initial yield strength, isotropic material hardening, and the equivalent plastic strain, respectively. $\boldsymbol{a}$ is the flow vector. The notation $\dot{\epsilon}$ denotes the time derivative $\frac{\partial \epsilon}{\partial t}$. Active yielding occurs when $f \geq 0$. The evolution equation for active yielding is $\dot{f}=0$.

\section{Boundary conditions}

The mechanical boundary condition mainly specifies the nodal constraints [43, 87, 99]. Usually, all nodes of the substrate at the bottom region are rigidly constrained [130-132] as they are fused with the bottom region of build part and no deformation occurred during the PBF process, while some spring constraints may be applied to model the elasticity of the clamps or supports [133]. The final distortion of the end part can only be obtained once the built part is fully cooled to the room temperature and the clamps or supports are removed. Therefore, an additional model should be developed to simulate the wipe off the supports and the baseplate from the end part $[131,132]$. 


\subsection{Assumptions and techniques used to accelerate the simulation process}

It should be noted that even a weak coupled thermo-mechanical analysis for a few scanning tracks with a fine mesh model would take many hours or many days to complete [43] depending on the model size and computer performance. To accelerate the simulation process, several assumptions and techniques have been made. For example, compared with the dimension of the part, the dimension of melt pool is very small. Then the convection of liquid in the melt pool is not considered in many studies $[43,134]$. During mechanical analysis, the powder layer volume shrinkage due to solidification and the metal vaporization are not considered as well [56, 76, 113]. Heat losses from the radiation of free surfaces are usually ignored $[72,81]$ as the inclusion of radiation loss will increase the non-linearity of the problem. In addition, heat losses from the bottom of the baseplate can be ignored [123]. These simplifications would lead to the decrease of analysis accuracy. However, the loss of accuracy is small because most of the thermal heat is conducted through the powder bed and solidified layers and the computational cost can be significantly reduced.

Apart from the above assumptions, several techniques have been applied to reduce the computational time and cost during the simulation process. A number of studies mainly focus on the modeling of heat source, changing the mesh density with the moving of heat source, and activating the powder in each scanning track and layer to reduce the computational cost.

\subsubsection{Heat source}

Heat source model plays a significant role in the modeling of PBF process. From equations (16) and (17), it can be noted that the heat source is a function of location and time. To simulate the applying of thermal heat into the powder bed, the time step should be small enough no matter what explicit time discretization method or implicit time discretization method is adopted so that the solution accuracy can be guaranteed. However, huge computational cost including time and storage space are required for such small time step. Some studies have considered the heat source as a temperature load $[102,105]$ to reduce the computational cost. While some other studies have modeled the scanning vectors with scanning areas instead of the exact scanning path $[122,135]$. In some cases, the thermal heat is applied to a whole layer to substitute the scanning path [136]. The computational cost can be definitely reduced, but these simplified heat source models cannot be able to describe the scanning strategy in a single layer. Recently, a new line heat source model instead of Gaussian moving point heat source model has been proposed [112] to simulate the AM process. The line heat source model is presented in Table 3. The basic idea is to elongate the semi-axis of the ellipsoidal heat distribution along scanning direction so that the total power distribution is the same with Goldak's ellipsoidal power distribution [106]. It claims that at each time increment, the simulation result sways within $10 \%$ displacement error and computational time is decreased to $1 / 10$ of the time required by using the moving heat source model.

\subsubsection{Element birth and death}

The addition of powder material in layer-based PBF process have presented challenges to previous research in creating 3D models and restricting most of the studies to model single tracks or single layer [137]. In order to simulate the deposition of powder onto the substrate with respect to time, the 'element birth and death' technique is applied to the 3D thermos-mechanical analysis $[28,118,137,138]$. The geometry model of the whole powder bed and printed part are built first and convert to the finite element model. Then all elements contained in the printed part will be 
killed or deactivated. The killed elements keep in the model but contribute a very small conductivity value to the total stiffness matrix, which means the deactivated elements have no contribution to the heat transfer process. When the laser/electron beam scans to a certain layer, the element within that layer will be activated and predefined conductivity coefficient and other parameters will be assigned to these elements again. Figure 5 describes the activation of the element with the moving of laser beam [95]. The activation sequence strictly follows the real experimental deposition, and there is idle time between consecutive layers to simulate the powder spreading process.

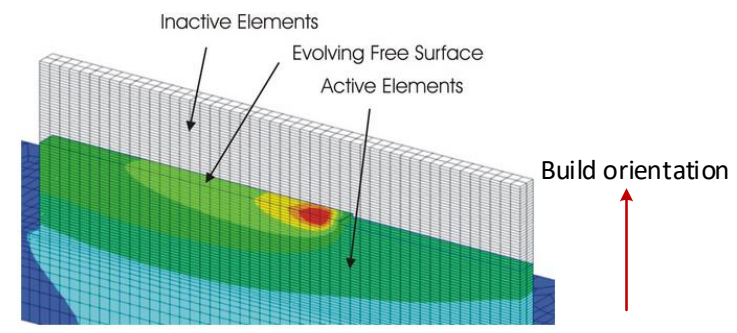

Figure 5. Element birth and death technique for the simulation of the deposition of powder [95]

\subsubsection{Adaptive mesh refinement}

It is well known that coarse mesh will result in big discretization error and refined mesh will result in small discretization error in the place where large solution gradient resides. However, the smaller the mesh the longer the computational time and the larger store space will be needed. Therefore, within the requirement of accuracy, how to reduce the computational cost is one of the problems needs to be solved. Clearly uniform finite element mesh cannot smooth the contradiction between solution accuracy and computational cost. If a non-uniform finite element mesh scheme is chosen which has smaller uniform mesh close to the melt pool and coarser uniform mesh far away from the melt pool, good accuracy with acceptable computational cost can be achieved. In addition, with the moving of the heat input, the region where the smaller mesh is occupied should also moves with the laser beam. And the region with smaller mesh should be restored to coarse mesh in the next load step, which has been discussed in section 2.1.4. As the temperature gradients near the melt pool are extremely high, a local adaptively refined mesh scheme should be used during the simulation process [139]. This adaptive mesh is able to reduce computational time and yield more accurate results compared to the static mesh scheme [140]. Dynamic adaptive mesh refinement technique has been widely used in the simulation of large deformation, forge forming, and fluid dynamics. Patil et al. [141] developed a type of adaptive meshing to model the additive manufacturing process. In this method, a box with the finer mesh that moves through a domain with coarser mesh is used to present the melt pool region. When the box with finer mesh moves, the properties of the new elements is then interpolated from the properties of the old elements. Therefore, the entire stiffness matrix doesn't need to be reassembled during every time step. The number of elements can also remain the same during the analysis so that the size of the model is always the same. By taking this method, the computation time can be greatly reduced.

\section{Thermo-mechanical model}

The transient temperature history of powder bed and solidified layers is crucial for calculating the thermal stress distribution and final residual stress in the built part. For weak coupled thermo- 
mechanical finite element analysis, after the temperature history has been obtained, a transient stress analysis will be executed. The obtained temperature history is applied as the thermal load for the mechanical analysis.

Followed the above-mentioned method in section 2, many FE models have been developed to estimate the temperature field and thermal stress field during the PBF process. Fu and Guo [20] developed a 3D FEM to simulate multilayer deposition of Ti-6AI-4V in SLM. The modeling process incorporates the layer accumulation approach and the moving heat source. Zhang et al. [142] developed a 3D FEM model to predict the temperature distribution of $90 \mathrm{~W}-7 \mathrm{Ni}-3 \mathrm{~F}$ part in SLM. Childs et al. [58] investigated the influence of laser power and scanning speed on the scanning track in the powder bed and found a proportional relationship between scanning speed and the mass of melted metal. Bugeda and Gabriel [7] developed a FEM to simulate the 3D sintering process of a single track during SLS process. The coupled model obtains useful results such as the temperature field, solid fraction and density distribution, and sintering depth. Gusarov et al. [143] proposed a model which combined the heat radiation to stabilize the SLM process to study a single track on a layer of the loose powder bed. The results show that the maximum temperature is slightly shifted away from the center of the laser beam and the melt pool is highly stretched along the scanning direction. Ma and Bin [102] proposed a model for estimating the evolution of temperature, thermal stress, and distortion within a single layer using different scanning patterns in SLS process. The results showed that fractal-scanning pattern could reduce the distortion and transient stresses. Dai and Shaw $[56,144]$ proposed a FEM to investigate the influence of scanning pattern, and scanning speed on the temperature field as well as stress field. Hussein et al. [36] developed a 3D non-linear transient FE model to investigate the temperature and stress distribution in the SLM. Denlinger and Heigel [28] model the in-situ thermo-mechanical stress and distortion of a Ti-6Al-4V part by a 3D thermal-elasto-plastic analysis. The simulation results show that the computed thermal history and computed distortion history displays $7.7 \%$ and $7.4 \%$ error with the measurement from experiment respectively. Zaeh and Branner [135] presented a model to simulate the transient physical effects in $\mathrm{AM}$ and identifies the heat impact on residual stress and deformations through a coupled thermo-mechanical model. Vasinonta and Beuth [145] presented a thermo-mechanical model which involving a moving heat source to build thin-walled structures. Another work [146] applied this model to investigate the variation of melt pool size with the increase of vertical free edge as well as tensile stress along the vertical direction at vertical free edges. Jiang et al. [62] presented a thermo-mechanical model to investigate the residual stress and deformation in direct laser sintering of stainless steel. The thermal model considers the nonlinear heat conduction with a moving Gaussian heat source and latent heat and temperature-dependent material properties.

From the review of existing studies, FE analysis of temperature distribution during SLM process is the most widely studied. This may attribute to the fact that compared to the SLM process, the EBM process results in less residual stress and distortion in final part due to the inclusion of preheating process. In addition, the investigation of residual stress and deformation in final part usually does not include the fluid dynamic of melt pool because of the small size of melt pool compared to that of the part being built and complicated phenomena happened in melt pool. Therefore, the simulation of temperature and thermal stress fields are also only limited to single track, one layer, or several layers due to the limitation of computational cost. 


\section{Simulation results}

\subsection{Geometry, temperature and stress fields of melting pool}

It's a significant challenge to measure and control the small size of melt pool and large temperature gradient. The size of the melt pool is slightly larger (about 10\%) than that of the laser beam [144], and it is greatly influenced by the applied energy density which is controlled by the input power and scanning speed. The scanning speed affects the capillary instability of the liquid scanning track [147], which results in pores or non-melted powders between layers. At high scanning speed, the length of the melt pool increases while both width and depth of the melt pool decrease.

The temperature gradient is much steeper on the front of the moving melt pool than that of the back side [36]. The melt pool has a shape of "comet tail profile" [20] as shown in Figure 6, which has a slant temperature distribution on the back of the laser beam [72]. The reason for this may be the fact that the cooled and solidified material has a higher conductivity property compared to the unheated powder in front of the energy source. The temperature gradient can be reduced by using more compact powder which would lead to higher thermal conductivity. Higher thermal conductivity can deliver more thermal energy into the bottom layers and thus reduce the temperature gradient. In PBF process, the temperature gradient along the depth direction is higher than that of the length direction and width direction since the powder material restricts the heat conduction along the depth direction. The remelting depth of each layer has proven to be significant to the microstructure evolution [148] and restrain balling effect [149]. Thus, it is critical to predict and control the melting depth of each layer during SLM. Xiao and Zhang [68] proposes a model to simulate the influence of the practical process parameters on strengthening the metallic bonding between adjacent layers and hatching lines. The overlaps between vertically deposited layers and horizontally adjacent hatching lines are taken into account to obtain the sound metallic bonding. The results show that the depth of melt pool decreases with the increase of scanning speed.

Compressive stress is developed during the melting process and transformed to tensile stress during the cooling cycle. The compressive stress resides in the melt pool. To equilibrate the force and momentum within the solidified layers, the melt pool will be surrounded by a zone of tensile stress [144]. Such stress distribution can be attributed to the relatively large thermal expansion of the melt pool and its nearby material at high temperature. Aggarangsi and Beuth [146] developed a model to investigate the variation of melt pool size with the increase of vertical free edge as well as tensile stress along the vertical direction at vertical free edges. Simulation results show that the size of melt pool has some impacts on the stresses distribution of free edge. 


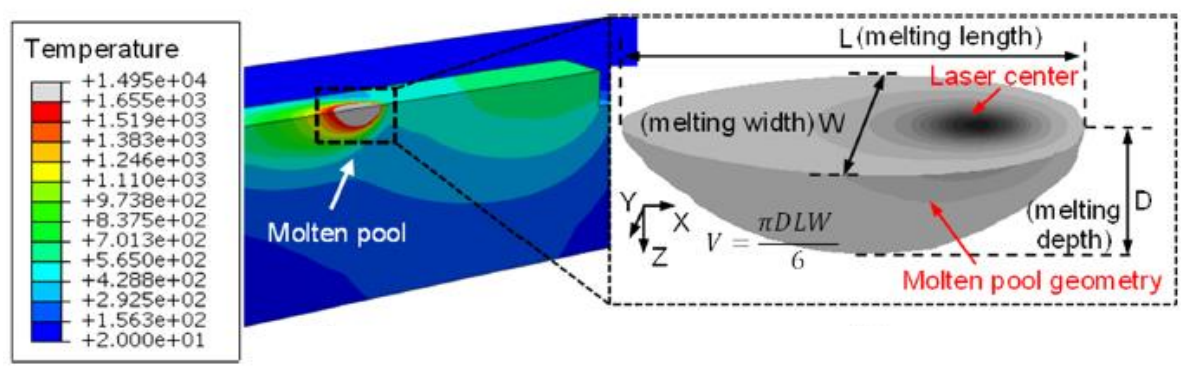

(a) Temperature contours and geometry of melt pool

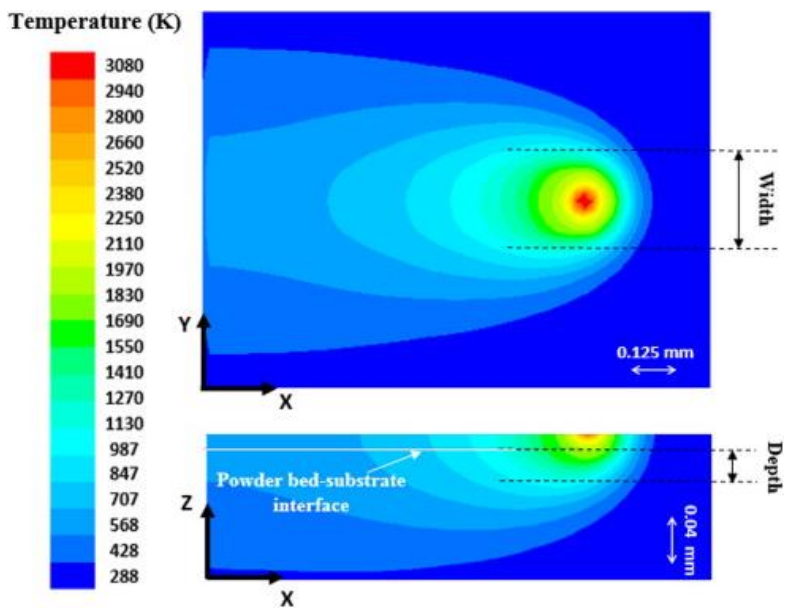

(b) Melt pool dimensions in the simulation of the melt pool morphology

Figure 6. Characteristics of melt pool [20, 150]

\subsection{Temperature and stress fields at the part level}

Many studies have achieved some specific findings to control or minimize the deformation of the final part by regulating the critical process parameters. For example, for the fabrication of an overhang feature, which has no underlying support structures to restrict the thermal stress, the material expands during the heating cycle and contracts during the cooling cycle. According to Jiang et al. [62], there are two mechanisms for deformation in laser melted part: shrinkage and thermal stress-induced deflection. These deformations result in the warping of part and loss of dimensional accuracy. Shrinkage mainly induces the deformation perpendicular to the scanning direction. The thermal load mainly induces the deformation along the scanning direction.

For the influence of scanning pattern, the length scanning direction results in larger residual stress compared to a local island scanning strategy [9] which has short scanning vectors. Ma and Bin [102] investigated the temperature and thermal stress fields by using two different scanning patterns in SLS. Simulation results show that the transient stress and the distortion decrease with fractal scanning pattern. Nickel et al. [55] found that scanning pattern has an important influence on the deformation of the fabricated part. Dai and Shaw [56] found that for a thin plate, the zigzag scanning pattern would lead to the concave upward distortion perpendicular to the scanning direction whereas concave downward distortion along the scanning direction and finally forms a saddle shape. Compared with the transient thermal stress, the residual thermal stress results in less distortion and opposite distortion direction.

For the influence of support structures, Zaeh and Branner [135] found that when built an overhang features with support structures, larger residual stress is shown in the intersection area 
between the supports and overhang plane which would lead to a delamination of supports from the part. And the simulation results show that the island-scanning pattern induces lower residual stress compare to that of the longitudinal scanning pattern.

For the influence of base plate, Denlinger et al. [28] discovered that the residual stress of deposited part is lower than that of the substrate. Because the temperature of deposited part repeatedly exceeds the stress relaxation temperature due to the melting of adjacent scanning tracks and upper layers. The repeated stress relaxation would lead to a decrease in residual stress. Mercelis et al. [46] comprehensively investigated the influence of the part removal from the baseplate, the number of layers, baseplate geometry, and yield strength on the residual stress of a part. The simulation and experiment results show that a thicker baseplate would result in a lower stress and more uniform stresses within the part and base plate. In addition, a high yield strength will induce a high stress. The final residual stresses increase with the increase of adding more layers. Furumoto et al. [51] evaluated the influence of baseplate thickness and part height on the residual stress as well as the effects of pre-heating of baseplate and post-heating of the solidified layer by a laser beam irradiation on the residual stress during the SLM process. The results show that the deformation of the base plate increases with the increase of solidified layer and the decrease of baseplate thickness.

A significant number of research has been devoted to investigating the relationship between process parameters and residual stress so that the deformation of the final part can be controlled or minimized. Table 4 lists the main impact factors that have significant impacts on the residual stress of the final part.

Table 4 Summary of impact factors on residual stress within final part

\begin{tabular}{|c|l|c|}
\hline Impact factors & \multicolumn{1}{|c|}{ Effects on end part } & References \\
\hline Base plate geometry & $\begin{array}{l}\text { thicker base plate leads to lower and more uniform } \\
\text { residual stress }\end{array}$ & {$[46,51]$} \\
\hline $\begin{array}{c}\text { Preheating of build } \\
\text { chamber (base plate) }\end{array}$ & $\begin{array}{l}\text { Preheating results in the reduction of temperature } \\
\text { gradient and thus reduced residual stress }\end{array}$ & {$[51,135]$} \\
\hline Build orientation & $\begin{array}{l}\text { Specific build orientation would lead to minimum } \\
\text { residual stress }\end{array}$ & {$[151-153]$} \\
\hline $\begin{array}{c}\text { Support structure } \\
\text { distribution }\end{array}$ & $\begin{array}{l}\text { Usually supports would reduce distortion } \\
\text { high residual stress }\end{array}$ & {$[36]$} \\
\hline Layer thickness & $\begin{array}{l}\text { thinner layer thickness results in higher stress and } \\
\text { deformation }\end{array}$ & {$[135]$} \\
\hline Layer geometry & $\begin{array}{l}\text { Related to specific geometry shape and their } \\
\text { accumulation lead to different residual stress }\end{array}$ & {$[135,154]$} \\
\hline Addition of layers & $\begin{array}{l}\text { The increase of adding more layers results in the } \\
\text { increase of residual stress }\end{array}$ & {$[46,51,155]$} \\
\hline
\end{tabular}




\begin{tabular}{|c|c|c|}
\hline $\begin{array}{l}\text { Scanning length } \\
\text { (direction) }\end{array}$ & $\begin{array}{l}\text { Long scanning vector generates large temperature } \\
\text { gradient and results in high residual stress }\end{array}$ & $\begin{array}{l}{[9,36,135,} \\
144,154]\end{array}$ \\
\hline $\begin{array}{l}\text { Scanning power \& } \\
\text { speed }\end{array}$ & higher energy density generates higher strain change & $\begin{array}{l}{[36,144,} \\
154]\end{array}$ \\
\hline Scanning pattern & $\begin{array}{l}\text { Stress decrease when applying fractal, spiral and small } \\
\text { piece scanning pattern }\end{array}$ & $\begin{array}{c}{[55,56,102,} \\
135,144, \\
154]\end{array}$ \\
\hline Scanning sequence & $\begin{array}{l}\text { the appropriate fabrication sequence would result in } \\
\text { reduced residual stress }\end{array}$ & [144] \\
\hline
\end{tabular}

\section{Experimental validation}

Either analytical solutions or numerical solutions are not enough to completely predict the temperature and thermal stress distribution in PBF process as underlying assumptions are simplified to deal with the model mathematically. Thus, in-process monitoring and measurement of the temperature distribution of the melt pool and powder bed are necessary to understand the temperature field development and to validate the numerical models. The measurement of residual stress and distortion are usually done in the post process. The measurement of temperature includes the temperature distribution of melt pool and powder bed. There are mainly two measurement methods: the contact method and the non-contact method. The contact method uses mostly thermocouples, which are installed in a limited space and contact with the object, to measure the temperature of melt pool or powder bed at a specific point. The non-contact method mainly uses a thermal camera to capture the temperature distribution of the melt pool and the powder bed. Various techniques for measuring the residual stress of AM processed part have been applied such as X-ray and neutron diffractions, ultrasonic velocity, hole drilling, layer removal techniques, and crack compliance.

Validation of the numerical model can be achieved through the comparison of simulation results with experimental results. It is shown experimentally that scanning speed and laser power have a significant impact on the melt pool size and cooling rate [156]. The width and depth of melt pool increase with the increase of energy input [157] and experiments have shown that melt pool length can affect the solidification process [158]. However, the width of the melt pool of experimental results is usually higher than that of calculated results [157]. This can be attributed to the inconsistency of the complex temperature-dependent material properties between experiment and numerical calculation. Higher energy density generates higher strain change, which results in more deformation. In addition, the repetition of thermal expansion and contraction complicate the residual stress of the final part. Zaeh and Branner [135] investigated the effects of overhang thickness, initial platform temperature, layer thickness, and scanning direction on the deformation within SLM processed parts. Experiment results show that a decreased layer thickness will increase the deformation of a layer. This is because that a higher temperature of the thin layer would lead to a high-temperature gradient along the thickness direction. Aziz et al. [154] investigated the thermal and strain behavior through the variation of strain and temperature at the baseplate. The experimental results show that the processing temperature affects the strain within the sintered structure during and after the sintering process. Less residual strain and higher residual stress-strain are found along the width of test part and the length of the test part, respectively. Shiomi et al. [155] studied the residual stress field within SLM 
processed part. The experimental results show that large tensile stress resides in the upper layer of the part. Inside the part, the tensile residual stress decreases with the increase of the distance from the upper surface.

Most of the validation experiment only focus on a single scanning track or simple geometries such as T-shape overhang, thin wall structure, most of which do not represent the complex geometrical features of slicing layer. The specimen should consider the complex geometry of real parts such as acute angle, overhang structures, hollow structures, and the intersection of two or more features.

\section{Conclusions and perspectives}

In this work, the implementation of finite element modeling of powder bed fusion process in macro-level is reviewed and discussed in detail. It first introduces several process deficiencies, which are mainly induced by the significant temperature gradient that occurs during the heating and cooling cycles. Most of these defects can be minimized through optimal process parameters. Compared with the experimental method, the finite element method is more efficient and economical to optimize the process parameters and achieve a final part with better mechanical performance. Then the numerical modeling methodologies are discussed comprehensively. In the pre-processing stage, the selection of part geometry and process parameters, temperaturedependent material models, choice of mesh schemes, and specification of heat source model as well as boundary conditions are discussed in detail. In the processing stage, the governing equations for the heat transfer in the thermal analysis and the thermal stress in the mechanical analysis are summarized. Considering the drawback of high computational cost in FEM, several simulation techniques and assumptions are outlined to accelerate the simulation process. After that, many recent developed thermos-mechanical FE models for PBF process are reviewed. Finally, the simulation results of temperature and thermal stress fields are validated through the experimental results.

Simulation and modeling of AM process have been widely studied in recent years. There are several reasons behind this. First, it can provide guidelines for the material design such as powder size, powder distribution in the build chamber, powder morphology, and chemical composition. This is because of the porosity of the powder bed, which is directly influenced by these parameters, determines the effective thermal conductivity and other material properties. The difference of these material properties could lead to significantly different quality of printed part. Although the experimental method is a good way to investigate the relationship between AM parts and powder properties, it involves a huge amount of time and cost. Finite element method enables people to do the qualitative and quantitative analysis of the basic process. For example, how the heat transferred from the thermal beam to the powder, how the morphology and composition of the powder impact the heat absorptivity, how to design material (or spread powder methods) so that thermal stress could be in control. Second, simulation and modeling of AM process would facilitate the optimization of process parameters and improve the mechanical and geometrical qualities of final printed parts. It has been shown in this review that many of the optimized process parameters have been sought out through the FE method and validated by experiments. However, there are still many unclear relationships between process parameters and defects in the end product (e.g. porosity, balling, warping, overheating, partially melting, non-connected layers). By conducting the research of process modeling and simulation, there is a great possibility to figure out some of the underlie mechanism and take corresponding control strategies to counteract the defections among the processed part. Third, simulation and modeling of AM process could clarify 
the crucial regions where in-process monitoring is highly recommended. On the other hand, inprocess monitoring and measurement results can also provide data to adjust and validate the model and finally improve the effectiveness and accuracy of the FEM for AM process. Therefore, as shown in Figure 7, simulation and modeling of AM process is the key technology, which connects almost every aspect of AM technology. The implementation of PBF simulation could facilitate the widespread of $A M$ among industries and increase the interest of the public in AM.

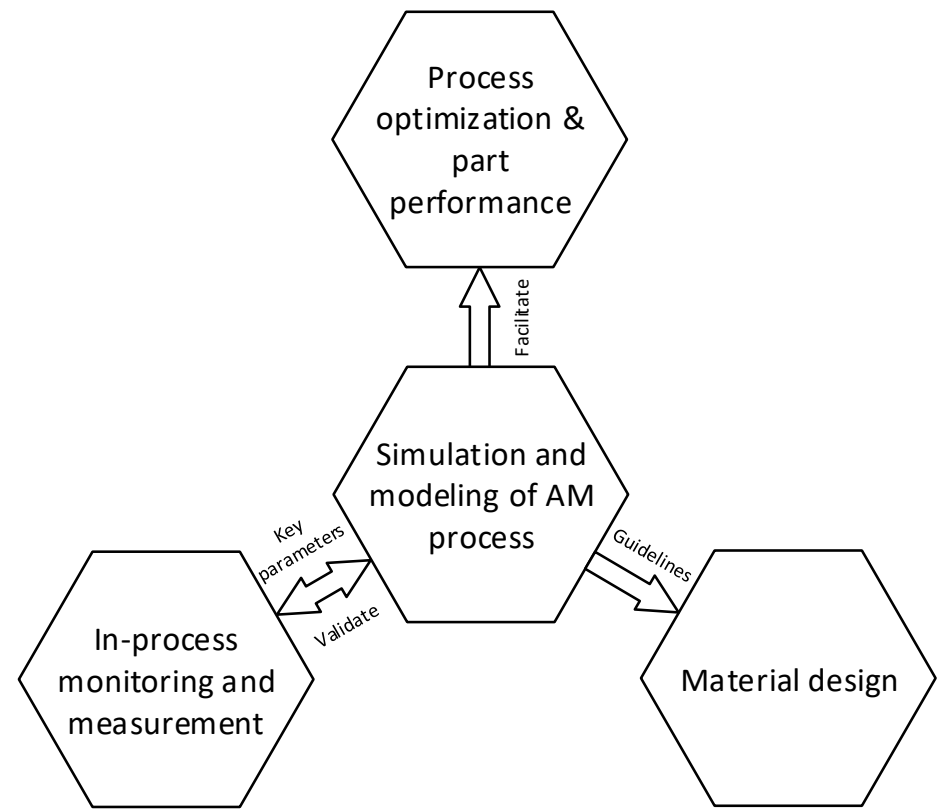

Figure 7. Relationships between AM modeling, simulation, and other AM aspects

However, there are still several issues need to be addressed. First, for the simulation of a practical part, the computational cost is still very high. How to reduce the computational cost without losing too much solution accuracy is the main concern. Parallel computing and cloud-based computing have emerged as the popular ways to accelerate the simulation process. Second, due to the complexity of various physical phenomena tangled with each other, the simplifying assumptions made on the boundary conditions, material properties, and uncoupled thermomechanical analysis introduce a certain discrepancy to some extent which can not be validated through experiments. To deal with this kind of black-box problem, data mining method is emerging as the possible way to untangle the relationship from statistical theory. Third, most of existing FEM does not incorporate the fluid dynamics of melt pool in the macro-level simulation. Therefore, the heat transfer and fluid flow among the melt pool cannot be tracked and included in the numerical analysis. In addition, modeling of melt pool dynamics in micro-level is simplified and cannot be directly applied to model the whole part in macro-level due to the huge computational cost. Fourth, the mesh is usually in quadrilateral (2D) or hexahedral (3D) shape, which is not the exact spherical or other irregular shapes of real powder, the continuity of material property is not the same with real powder material. Therefore, traditional FEA tools are not capable of accurately simulating the material properties. To deal with the above-mentioned problems, hybrid modeling method in macro-level and micro-level is a good way to balance the computational cost and solution accuracy. Another way to optimize the process parameters is the newly emerged data mining method. Data mining method has the ability to grab the key factors from the experiment or simulation result to predict the desired melt pool properties and other thermo-mechanical properties of the part. To summarize, new finite element method which 
combines macro-level elements in the powder bed and micro-level elements in the melt pool, and data mining are the two different but promising methods to investigate the optimization of PBF process parameters.

\section{Acknowledgement}

This work was supported by National Science and Engineering Research Council of Canada Discovery Grant RGPIN 436055-2013; and China Scholarship Council (201406020102).

\section{References}

[1] A. Standard, "F2792. 2012 Standard terminology for additive manufacturing technologies," West Conshohocken, PA: ASTM International. See www. astm. org.(doi: 10.1520/F2792-12), 2012.

[2] G. Tapia and A. Elwany, "A Review on Process Monitoring and Control in Metal-Based Additive Manufacturing," Journal of Manufacturing Science and Engineering, vol. 136, p. 060801, 2014.

[3] I. Gibson, D. W. Rosen, and B. Stucker, Additive manufacturing technologies: Springer, 2010.

[4] K. V. Wong and A. Hernandez, "A review of additive manufacturing," ISRN Mechanical Engineering, vol. 2012, 2012.

[5] J.-P. Kruth, G. Levy, F. Klocke, and T. Childs, "Consolidation phenomena in laser and powder-bed based layered manufacturing," CIRP Annals-Manufacturing Technology, vol. 56, pp. 730-759, 2007.

[6] H. Krauss, C. Eschey, and M. Zaeh, "Thermography for monitoring the selective laser melting process," in Proceedings of the 23rd Annual International Solid Freeform Fabrication Symposium, edited by D. Bourell, R. Crawford, C. Seepersad, J. Beaman, and H. Marcus (The University of Texas at Austin, Austin, TX, 2012), 2012.

[7] G. Bugeda Miguel Cervera and G. Lombera, "Numerical prediction of temperature and density distributions in selective laser sintering processes," Rapid Prototyping Journal, vol. 5, pp. 21-26, 1999.

[8] J. Slotwinski, "Additive manufacturing: Overview and NDE challenges," in 4OTH ANNUAL REVIEW OF PROGRESS IN QUANTITATIVE NONDESTRUCTIVE EVALUATION: Incorporating the 10th International Conference on Barkhausen Noise and Micromagnetic Testing, 2014, pp. 1173-1177.

[9] J.-P. Kruth, L. Froyen, J. Van Vaerenbergh, P. Mercelis, M. Rombouts, and B. Lauwers, "Selective laser melting of iron-based powder," Journal of Materials Processing Technology, vol. 149, pp. 616-622, 2004.

[10] B. Vandenbroucke and J.-P. Kruth, "Selective laser melting of biocompatible metals for rapid manufacturing of medical parts," Rapid Prototyping Journal, vol. 13, pp. 196-203, 2007. 
[11] A. T. Clare, P. R. Chalker, S. Davies, C. J. Sutcliffe, and S. Tsopanos, "Selective laser melting of high aspect ratio 3D nickel-titanium structures two way trained for MEMS applications," International Journal of Mechanics and Materials in Design, vol. 4, pp. 181-187, 2008.

[12] D. A. Hollander, M. Von Walter, T. Wirtz, R. Sellei, B. Schmidt-Rohlfing, O. Paar, et al., "Structural, mechanical and in vitro characterization of individually structured Ti-6Al-4V produced by direct laser forming," Biomaterials, vol. 27, pp. 955-963, 2006.

[13] P. Rochus, J.-Y. Plesseria, M. Van Elsen, J.-P. Kruth, R. Carrus, and T. Dormal, "New applications of rapid prototyping and rapid manufacturing (RP/RM) technologies for space instrumentation," Acta Astronautica, vol. 61, pp. 352-359, 2007.

[14] M. Wong, S. Tsopanos, C. J. Sutcliffe, and I. Owen, "Selective laser melting of heat transfer devices," Rapid Prototyping Journal, vol. 13, pp. 291-297, 2007.

[15] D. Buchbinder, H. Schleifenbaum, S. Heidrich, W. Meiners, and J. Bültmann, "High Power Selective Laser Melting (HP SLM) of Aluminum Parts," Physics Procedia, vol. 12, Part A, pp. 271-278, // 2011.

[16] S. Das, "Physical aspects of process control in selective laser sintering of metals," Advanced Engineering Materials, vol. 5, pp. 701-711, 2003.

[17] T. Habijan, C. Haberland, H. Meier, J. Frenzel, J. Wittsiepe, C. Wuwer, et al., "The biocompatibility of dense and porous nickel-titanium produced by selective laser melting," Materials Science and Engineering: C, vol. 33, pp. 419-426, 2013.

[18] S. Kumar and J.-P. Kruth, "Composites by rapid prototyping technology," Materials \& Design, vol. 31, pp. 850-856, 2010.

[19] V. Petrovic, J. Vicente Haro Gonzalez, O. Jorda Ferrando, J. Delgado Gordillo, J. Ramon Blasco Puchades, and L. Portoles Grinan, "Additive layered manufacturing: sectors of industrial application shown through case studies," International Journal of Production Research, vol. 49, pp. 1061-1079, 2011.

[20] C. Fu and Y. Guo, "Three-Dimensional Temperature Gradient Mechanism in Selective Laser Melting of Ti-6Al-4V," Journal of Manufacturing Science and Engineering, vol. 136, p. 061004, 2014.

[21] C. Körner, E. Attar, and P. Heinl, "Mesoscopic simulation of selective beam melting processes," Journal of Materials Processing Technology, vol. 211, pp. 978-987, 2011.

[22] R. Ippolito, L. Iuliano, and A. Gatto, "Benchmarking of rapid prototyping techniques in terms of dimensional accuracy and surface finish," CIRP Annals-Manufacturing Technology, vol. 44, pp. 157-160, 1995.

[23] H. J. Yang, P. J. Hwang, and S. H. Lee, "A study on shrinkage compensation of the SLS process by using the Taguchi method," International Journal of Machine Tools and Manufacture, vol. 42, pp. 1203-1212, 9// 2002.

[24] A. Bauereiß, T. Scharowsky, and C. Körner, "Defect generation and propagation mechanism during additive manufacturing by selective beam melting," Journal of Materials Processing Technology, 2014. 
[25] A. S. Wu, D. W. Brown, M. Kumar, G. F. Gallegos, and W. E. King, "An experimental investigation into additive manufacturing-induced residual stresses in 316L stainless steel," Metallurgical and Materials Transactions A, vol. 45, pp. 6260-6270, 2014.

[26] A. Hussein, L. Hao, C. Yan, R. Everson, and P. Young, "Advanced lattice support structures for metal additive manufacturing," Journal of Materials Processing Technology, vol. 213, pp. 1019-1026, 2013.

[27] J. Jhabvala, E. Boillat, C. André, and R. Glardon, "An innovative method to build support structures with a pulsed laser in the selective laser melting process," The International Journal of Advanced Manufacturing Technology, vol. 59, pp. 137-142, 2012.

[28] E. R. Denlinger, J. C. Heigel, and P. Michaleris, "Residual stress and distortion modeling of electron beam direct manufacturing Ti-6Al-4V," Proceedings of the Institution of Mechanical Engineers, Part B: Journal of Engineering Manufacture, p. 0954405414539494, 2014.

[29] K. Zeng, D. Pal, and B. Stucker, "A review of thermal analysis methods in Laser Sintering and Selective Laser Melting," in Solid Freeform Fabrication Symposium, 2012, p. 796.

[30] B. Schoinochoritis, D. Chantzis, and K. Salonitis, "Simulation of metallic powder bed additive manufacturing processes with the finite element method: A critical review," Proceedings of the Institution of Mechanical Engineers, Part B: Journal of Engineering Manufacture, p. 0954405414567522, 2015.

[31] M. Markl and C. Körner, "Multi-Scale Modeling of Powder-Bed-Based Additive Manufacturing," Annual Review of Materials Research, vol. 46, pp. 1-34, 2016.

[32] N. P. Lavery, S. G. Brown, J. Sienz, J. Cherry, and F. Belblidia, "A review of Computational Modelling of Additive Layer Manufacturing-multi-scale and multi-physics," Sustainable Design and Manufacturing 2014 Part 2, p. 668, 2014.

[33] J. N. Reddy and D. K. Gartling, The finite element method in heat transfer and fluid dynamics: CRC press, 2010.

[34] S. Kolossov, E. Boillat, R. Glardon, P. Fischer, and M. Locher, "3D FE simulation for temperature evolution in the selective laser sintering process," International Journal of Machine Tools and Manufacture, vol. 44, pp. 117-123, 2004.

[35] N. Contuzzi, S. Campanelli, and A. Ludovico, "3 D FINITE ELEMENT ANALYSIS IN THE SELECTIVE LASER MELTING PROCESS," International Journal of Simulation Modelling, vol. 10, pp. 113-121, 2011.

[36] A. Hussein, L. Hao, C. Yan, and R. Everson, "Finite element simulation of the temperature and stress fields in single layers built without-support in selective laser melting," Materials \& Design, vol. 52, pp. 638-647, 12// 2013.

[37] L. Van Belle, G. Vansteenkiste, and J. C. Boyer, "Comparisons of numerical modelling of the Selective Laser Melting," in Key Engineering Materials, 2012, pp. 1067-1072.

[38] M. Matsumoto, M. Shiomi, K. Osakada, and F. Abe, "Finite element analysis of single layer forming on metallic powder bed in rapid prototyping by selective laser processing," International Journal of Machine Tools and Manufacture, vol. 42, pp. 61-67, 2002. 
[39] P.-k. BAI, J. CHENG, L. Bin, and W.-f. WANG, "Numerical simulation of temperature field during selective laser sintering of polymer-coated molybdenum powder," Transactions of Nonferrous Metals Society of China, vol. 16, pp. s603-s607, 2006.

[40] T. Childs, M. Berzins, G. Ryder, and A. Tontowi, "Selective laser sintering of an amorphous polymer-simulations and experiments," Proceedings of the Institution of Mechanical Engineers, Part B: Journal of Engineering Manufacture, vol. 213, pp. 333-349, 1999.

[41] B. Song, S. Dong, H. Liao, and C. Coddet, "Process parameter selection for selective laser melting of Ti6Al4V based on temperature distribution simulation and experimental sintering," The International Journal of Advanced Manufacturing Technology, vol. 61, pp. 967-974, 2012.

[42] N. Shen and Y. Chou, "Numerical thermal analysis in electron beam additive manufacturing with preheating effects," in Proceedings of the 23rd Solid Freeform Fabrication Symposium, Austin, TX, 2012, pp. 774-784.

[43] B. Cheng, S. Shrestha, and K. Chou, "Stress and deformation evaluations of scanning strategy effect in selective laser melting," Additive Manufacturing, 2016.

[44] R. Paul, S. Anand, and F. Gerner, "Effect of thermal deformation on part errors in metal powder based additive manufacturing processes," Journal of Manufacturing Science and Engineering, Transactions of the ASME, vol. 136, 2014.

[45] N. E. Hodge, R. M. Ferencz, and J. M. Solberg, "Implementation of a thermomechanical model for the simulation of selective laser melting," Computational Mechanics, vol. 54, pp. 33-51, 2014.

[46] P. Mercelis and J.-P. Kruth, "Residual stresses in selective laser sintering and selective laser melting," Rapid Prototyping Journal, vol. 12, pp. 254-265, 2006.

[47] P. Fischer, M. Locher, V. Romano, H.-P. Weber, S. Kolossov, and R. Glardon, "Temperature measurements during selective laser sintering of titanium powder," International Journal of Machine Tools and Manufacture, vol. 44, pp. 1293-1296, 2004.

[48] S. Tsopanos, R. Mines, S. McKown, Y. Shen, W. Cantwell, W. Brooks, et al., "The influence of processing parameters on the mechanical properties of selectively laser melted stainless steel microlattice structures," Journal of Manufacturing Science and Engineering, vol. 132, p. 041011, 2010.

[49] D. Wang, Y. Yang, Z. Yi, and X. Su, "Research on the fabricating quality optimization of the overhanging surface in SLM process," The International Journal of Advanced Manufacturing Technology, vol. 65, pp. 1471-1484, 2013.

[50] Z. Jian, L. Deying, Z. Longzhi, and Z. Mingjuan, "Simulation of temperature field in selective laser sintering of copper powder," in Mechanic Automation and Control Engineering (MACE), 2010 International Conference on, 2010, pp. 3282-3285.

[51] T. Furumoto, T. Ueda, A. Aziz, M. Sanusi, A. Hosokawa, and R. Tanaka, "Study on reduction of residual stress induced during rapid tooling process: Influence of heating conditions on residual stress," Key Engineering Materials, vol. 447, pp. 785-789, 2010. 
[52] A. Chatterjee, S. Kumar, P. Saha, P. Mishra, and A. R. Choudhury, "An experimental design approach to selective laser sintering of low carbon steel," Journal of Materials Processing Technology, vol. 136, pp. 151-157, 2003.

[53] C. Li, C. Fu, Y. Guo, and F. Fang, "Fast Prediction and Validation of Part Distortion in Selective Laser Melting."

[54] I. Yadroitsev and I. Yadroitsava, "Evaluation of residual stress in stainless steel 316L and Ti6Al4V samples produced by selective laser melting," Virtual and Physical Prototyping, 2015.

[55] A. Nickel, D. Barnett, and F. Prinz, "Thermal stresses and deposition patterns in layered manufacturing," Materials Science and Engineering: A, vol. 317, pp. 59-64, 2001.

[56] K. Dai and L. Shaw, "Distortion minimization of laser-processed components through control of laser scanning patterns," Rapid Prototyping Journal, vol. 8, pp. 270-276, 2002.

[57] E. Foroozmehr and R. Kovacevic, "Effect of path planning on the laser powder deposition process: thermal and structural evaluation," The International Journal of Advanced Manufacturing Technology, vol. 51, pp. 659-669, 2010.

[58] T. Childs, C. Hauser, and M. Badrossamay, "Selective laser sintering (melting) of stainless and tool steel powders: experiments and modelling," Proceedings of the Institution of Mechanical Engineers, Part B: Journal of Engineering Manufacture, vol. 219, pp. 339-357, 2005.

[59] K. Masubuchi, Analysis of welded structures: Residual stresses, distortion, and their consequences vol. 33: Elsevier, 2013.

[60] A. Gusarov and J.-P. Kruth, "Modelling of radiation transfer in metallic powders at laser treatment," International Journal of Heat and Mass Transfer, vol. 48, pp. 3423-3434, 2005.

[61] A. Gusarov and E. Kovalev, "Model of thermal conductivity in powder beds," Physical Review B, vol. 80, p. 024202, 2009.

[62] W. Jiang, K. Dalgarno, and T. Childs, "Finite Element Analysis of Residual Stresses and Deformations in Direct Metal SLS Process," in Proc. of 13th Solid Freeform Fabrication Symposium, 2002, pp. 5-7.

[63] R. B. Patil and V. Yadava, "Finite element analysis of temperature distribution in single metallic powder layer during metal laser sintering," International Journal of Machine Tools and Manufacture, vol. 47, pp. 1069-1080, 2007.

[64] M. Shiomi, A. Yoshidome, F. Abe, and K. Osakada, "Finite element analysis of melting and solidifying processes in laser rapid prototyping of metallic powders," International Journal of Machine Tools and Manufacture, vol. 39, pp. 237-252, 1999.

[65] I. Yadroitsev, A. Gusarov, I. Yadroitsava, and I. Smurov, "Single track formation in selective laser melting of metal powders," Journal of Materials Processing Technology, vol. 210, pp. 1624-1631, 9/1/ 2010. 
[66] N. K. Tolochko, Y. V. Khlopkov, S. E. Mozzharov, M. B. Ignatiev, T. Laoui, and V. I. Titov, "Absorptance of powder materials suitable for laser sintering," Rapid Prototyping Journal, vol. 6, pp. 155-161, 2000.

[67] T. Childs, C. Hauser, C. Taylor, and A. Tontowi, "Simulation and experimental verification of crystalline polymer and direct metal selective laser sintering," in Proc. SFF Symp., Austin, 2000, pp. 100-109.

[68] B. Xiao and Y. Zhang, "Laser sintering of metal powders on top of sintered layers under multiple-line laser scanning," Journal of Physics D: Applied Physics, vol. 40, p. 6725, 2007.

[69] L. Dong, A. Makradi, S. Ahzi, and Y. Remond, "Three-dimensional transient finite element analysis of the selective laser sintering process," Journal of materials processing technology, vol. 209, pp. 700-706, 2009.

[70] K. Antony, N. Arivazhagan, and K. Senthilkumaran, "Numerical and experimental investigations on laser melting of stainless steel 316L metal powders," Journal of Manufacturing Processes, vol. 16, pp. 345-355, 2014.

[71] P. K. Venuvinod and W. Ma, Rapid prototyping: laser-based and other technologies: Springer Science \& Business Media, 2013.

[72] I. A. Roberts, C. J. Wang, R. Esterlein, M. Stanford, and D. J. Mynors, "A three-dimensional finite element analysis of the temperature field during laser melting of metal powders in additive layer manufacturing," International Journal of Machine Tools and Manufacture, vol. 49, pp. 916-923, 10// 2009.

[73] M. Rombouts, L. Froyen, A. Gusarov, E. H. Bentefour, and C. Glorieux, "Photopyroelectric measurement of thermal conductivity of metallic powders," Journal of applied physics, vol. 97, p. 024905, 2005.

[74] M. Rombouts, L. Froyen, A. Gusarov, E. H. Bentefour, and C. Glorieux, "Light extinction in metallic powder beds: Correlation with powder structure," Journal of applied physics, vol. 98, p. 013533, 2005.

[75] T. Chen and Y. Zhang, "Three-dimensional modeling of laser sintering of a two-component metal powder layer on top of sintered layers," Journal of manufacturing science and engineering, vol. 129, pp. 575-582, 2007.

[76] N. K. Tolochko, M. K. Arshinov, A. V. Gusarov, V. I. Titov, T. Laoui, and L. Froyen, "Mechanisms of selective laser sintering and heat transfer in Ti powder," Rapid Prototyping Journal, vol. 9, pp. 314-326, 2003.

[77] S. Yagi and D. Kunii, "Studies on effective thermal conductivities in packed beds," AlChE Journal, vol. 3, pp. 373-381, 1957.

[78] M.-s. M. Sun and J. J. Beaman, "A three dimensional model for selective laser sintering," in Proceedings of Solid Freeform Fabrication Symposium, 1991, pp. 102-109.

[79] Y. Gao, J. Xing, J. Zhang, N. Luo, and H. Zheng, "Research on measurement method of selective laser sintering (SLS) transient temperature," Optik-International Journal for Light and Electron Optics, vol. 119, pp. 618-623, 2008. 
[80] P. Zehner and E. Schlünder, "Wärmeleitfähigkeit von Schüttungen bei mäßigen Temperaturen," Chemie Ingenieur Technik, vol. 42, pp. 933-941, 1970.

[81] J. Yin, H. Zhu, L. Ke, W. Lei, C. Dai, and D. Zuo, "Simulation of temperature distribution in single metallic powder layer for laser micro-sintering," Computational Materials Science, vol. 53, pp. 333-339, 2012.

[82] N. Shen and K. Chou, "Thermal modeling of electron beam additive manufacturing process: Powder sintering effects," in ASME 2012 International Manufacturing Science and Engineering Conference collocated with the 40th North American Manufacturing Research Conference and in participation with the International Conference on Tribology Materials and Processing, 2012, pp. 287-295.

[83] F. Liu, Q. Zhang, W. Zhou, J. Zhao, and J. Chen, "Micro scale 3D FEM simulation on thermal evolution within the porous structure in selective laser sintering," Journal of Materials Processing Technology, vol. 212, pp. 2058-2065, 2012.

[84] Y. Li and D. Gu, "Parametric analysis of thermal behavior during selective laser melting additive manufacturing of aluminum alloy powder," Materials \& Design, vol. 63, pp. 856867, 2014.

[85] U. Gaur, B. B. Wunderlich, and B. Wunderlich, "Heat capacity and other thermodynamic properties of linear macromolecules. VII. Other carbon backbone polymers," Journal of Physical and Chemical Reference Data, vol. 12, pp. 29-63, 1983.

[86] M. Boivineau, C. Cagran, D. Doytier, V. Eyraud, M.-H. Nadal, B. Wilthan, et al., "Thermophysical properties of solid and liquid Ti-6AI-4V (TA6V) alloy," International journal of thermophysics, vol. 27, pp. 507-529, 2006.

[87] M. Megahed, H.-W. Mindt, N. N’Dri, H. Duan, and O. Desmaison, "Metal additivemanufacturing process and residual stress modeling," Integrating Materials and Manufacturing Innovation, vol. 5, pp. 1-33, 2016.

[88] S. Kelly and S. Kampe, "Microstructural evolution in laser-deposited multilayer Ti-6Al-4V builds: Part II. Thermal modeling," Metallurgical and Materials Transactions A, vol. 35, pp. 1869-1879, 2004.

[89] P. Peyre, P. Aubry, R. Fabbro, R. Neveu, and A. Longuet, "Analytical and numerical modelling of the direct metal deposition laser process," Journal of Physics D: Applied Physics, vol. 41, p. 025403, 2008.

[90] M. N. Ahsan and A. J. Pinkerton, "An analytical-numerical model of laser direct metal deposition track and microstructure formation," Modelling and Simulation in Materials Science and Engineering, vol. 19, p. 055003, 2011.

[91] A. Longuet, Y. Robert, E. Aeby-Gautier, B. Appolaire, J. Mariage, C. Colin, et al., "A multiphase mechanical model for Ti-6Al-4V: Application to the modeling of laser assisted processing," Computational Materials Science, vol. 46, pp. 761-766, 2009.

[92] E. Haque and P. Hampson, "Modelling phase change in a 3D thermal transient analysis," The International Journal of Multiphysics, vol. 8, pp. 49-68, 2014. 
[93] K. Zeng, D. Pal, H. Gong, N. Patil, and B. Stucker, "Comparison of 3DSIM thermal modelling of selective laser melting using new dynamic meshing method to ANSYS," Materials Science and Technology, vol. 31, pp. 945-956, 2015.

[94] W. Bangerth, R. Hartmann, and G. Kanschat, "deal. II-a general-purpose object-oriented finite element library," ACM Transactions on Mathematical Software (TOMS), vol. 33, p. 24, 2007.

[95] P. Michaleris, "Modeling metal deposition in heat transfer analyses of additive manufacturing processes," Finite Elements in Analysis and Design, vol. 86, pp. 51-60, 9/1/ 2014.

[96] C. Li, J. Liu, Y. Guo, and Z. Li, "A Temperature-Thread Multiscale Modeling Approach for Efficient Prediction of Part Distortion by Selective Laser Melting."

[97] J. Ren, J. Liu, and J. Yin, "Simulation of transient temperature field in the selective laser sintering process of W/Ni powder mixture," in International Conference on Computer and Computing Technologies in Agriculture, 2010, pp. 494-503.

[98] E. R. Denlinger and P. Michaleris, "Effect of stress relaxation on distortion in additive manufacturing process modeling," Additive Manufacturing, vol. 12, Part A, pp. 51-59, 10// 2016.

[99] A. J. Dunbar, E. R. Denlinger, M. F. Gouge, and P. Michaleris, "Experimental validation of finite element modeling for laser powder bed fusion deformation," Additive Manufacturing, vol. 12, Part A, pp. 108-120, 10// 2016.

[100] D. Pal, N. Patil, M. Nikoukar, K. Zeng, K. H. Kutty, and B. E. Stucker, "An integrated approach to cyber-enabled additive manufacturing using physics based, coupled multi-scale process modeling," in Proceedings of SFF Symposium, Austin, TX, Aug, 2013, pp. 12-14.

[101] D. Pal, N. Patil, K. H. Kutty, K. Zeng, A. Moreland, A. Hicks, et al., "A Generalized FeedForward Dynamic Adaptive Mesh Refinement and Derefinement Finite-Element Framework for Metal Laser Sintering-Part II: Nonlinear Thermal Simulations and Validations," Journal of Manufacturing Science and Engineering, vol. 138, p. 061003, 2016.

[102] L. Ma and H. Bin, "Temperature and stress analysis and simulation in fractal scanning-based laser sintering," The International Journal of Advanced Manufacturing Technology, vol. 34, pp. 898-903, 2007.

[103] B. Cheng, S. Price, J. Lydon, K. Cooper, and K. Chou, "On Process Temperature in PowderBed Electron Beam Additive Manufacturing: Model Development and Validation," Journal of Manufacturing Science and Engineering, vol. 136, p. 061018, 2014.

[104] D. Pal, N. Patil, K. Zeng, C. Teng, S. Xu, T. Sublette, et al., "Enhancing Simulations of Additive Manufacturing Processes using Spatiotemporal Multiscaling," Proceedings of the Solid Freeform Fabrication SymposiumAustin, TX, 2014.

[105] C. Li, C. H. Fu, Y. B. Guo, and F. Z. Fang, "A multiscale modeling approach for fast prediction of part distortion in selective laser melting," Journal of Materials Processing Technology, vol. 229, pp. 703-712, 2016. 
[106] J. Goldak, A. Chakravarti, and M. Bibby, "A new finite element model for welding heat sources," Metallurgical transactions B, vol. 15, pp. 299-305, 1984.

[107] L. E. Criales, Y. M. Arısoy, B. Lane, S. Moylan, A. Donmez, and T. Özel, "Predictive modeling and optimization of multi-track processing for laser powder bed fusion of nickel alloy 625," Additive Manufacturing.

[108] P. Fischer, V. Romano, H.-P. Weber, N. Karapatis, E. Boillat, and R. Glardon, "Sintering of commercially pure titanium powder with a Nd: YAG laser source," Acta Materialia, vol. 51, pp. 1651-1662, 2003.

[109] J. Smith, W. Xiong, W. Yan, S. Lin, P. Cheng, O. L. Kafka, et al., "Linking process, structure, property, and performance for metal-based additive manufacturing: computational approaches with experimental support," Computational Mechanics, vol. 57, pp. 583-610, 2016.

[110] H. Gong, K. Rafi, T. Starr, and B. Stucker, "The Effects of Processing Parameters on Defect Regularity in Ti-6Al-4V Parts Fabricated By Selective Laser Melting and Electron Beam Melting," 2013.

[111] Y. Huang, M. B. Khamesee, and E. Toyserkani, "A comprehensive analytical model for laser powder-fed additive manufacturing," Additive Manufacturing, vol. 12, Part A, pp. 90-99, $10 / / 2016$.

[112] J. Irwin and P. Michaleris, "A Line Heat Input Model for Additive Manufacturing," in ASME 2015 International Manufacturing Science and Engineering Conference, 2015, pp. V001T02A019-V001T02A019.

[113] D. Dai and D. Gu, "Thermal behavior and densification mechanism during selective laser melting of copper matrix composites: Simulation and experiments," Materials \& Design, vol. 55, pp. 482-491, 3// 2014.

[114] M. X. Gan and C. H. Wong, "Practical support structures for selective laser melting," Journal of Materials Processing Technology, vol. 238, pp. 474-484, 12// 2016.

[115] L. Dong, J. P. M. Correia, N. Barth, and S. Ahzi, "Finite element simulations of temperature distribution and of densification of a titanium powder during metal laser sintering," Additive Manufacturing.

[116] Y. Huang, L. J. Yang, X. Z. Du, and Y. P. Yang, "Finite element analysis of thermal behavior of metal powder during selective laser melting," International Journal of Thermal Sciences, vol. 104, pp. 146-157, 6// 2016.

[117] D. Gu and B. He, "Finite element simulation and experimental investigation of residual stresses in selective laser melted Ti-Ni shape memory alloy," Computational Materials Science, vol. 117, pp. 221-232, 5// 2016.

[118] L.-E. Lindgren, A. Lundbäck, M. Fisk, R. Pederson, and J. Andersson, "Simulation of additive manufacturing using coupled constitutive and microstructure models," Additive Manufacturing. 
[119] L. Parry, I. A. Ashcroft, and R. D. Wildman, "Understanding the effect of laser scan strategy on residual stress in selective laser melting through thermo-mechanical simulation," Additive Manufacturing, vol. 12, Part A, pp. 1-15, 10// 2016.

[120] X. Bai, H. Zhang, and G. Wang, "Improving prediction accuracy of thermal analysis for weldbased additive manufacturing by calibrating input parameters using IR imaging," The International Journal of Advanced Manufacturing Technology, vol. 69, pp. 1087-1095, 2013.

[121] B. Cheng and K. Chou, "Geometric consideration of support structures in part overhang fabrications by electron beam additive manufacturing," Computer-Aided Design, vol. 69, pp. 102-111, 2015.

[122] J. Schilp, C. Seidel, H. Krauss, and J. Weirather, "Investigations on temperature fields during laser beam melting by means of process monitoring and multiscale process modelling," Advances in Mechanical Engineering, vol. 6, p. 217584, 2014.

[123] J. Zhang, D. Li, J. Li, and L. Zhao, "Numerical simulation of temperature field in selective laser sintering," in International Conference on Computer and Computing Technologies in Agriculture, 2010, pp. 474-479.

[124] M. Zain-ul-Abdein, D. Nelias, J.-F. Jullien, and D. Deloison, "Prediction of laser beam welding-induced distortions and residual stresses by numerical simulation for aeronautic application," Journal of Materials Processing Technology, vol. 209, pp. 2907-2917, 3/19/ 2009.

[125] K. Dai and L. Shaw, "Finite element analysis of the effect of volume shrinkage during laser densification," Acta materialia, vol. 53, pp. 4743-4754, 2005.

[126] G. A. Moraitis and G. N. Labeas, "Residual stress and distortion calculation of laser beam welding for aluminum lap joints," Journal of Materials Processing Technology, vol. 198, pp. $260-269,3 / 3 / 2008$.

[127] H. Liu, "Numerical analysis of thermal stress and deformation in multi-layer laser metal deposition process," 2014.

[128] F. Kong and R. Kovacevic, "3D finite element modeling of the thermally induced residual stress in the hybrid laser/arc welding of lap joint," Journal of Materials Processing Technology, vol. 210, pp. 941-950, 2010.

[129] J. C. Heigel, P. Michaleris, and E. W. Reutzel, "Thermo-mechanical model development and validation of directed energy deposition additive manufacturing of Ti-6Al-4V," Additive Manufacturing, vol. 5, pp. 9-19, 1// 2015.

[130] N. Keller and V. Ploshikhin, "New method for fast predictions of residual stress and distortion of AM parts," in Solid Freeform Fabrication Symposium, Austin, Texas, 2014, pp. 1229-1237.

[131] L. Papadakis, A. Loizou, J. Risse, S. Bremen, and J. Schrage, "A computational reduction model for appraising structural effects in selective laser melting manufacturing: A methodical model reduction proposed for time-efficient finite element analysis of larger components in Selective Laser Melting," Virtual and Physical Prototyping, vol. 9, pp. 17-25, 2014. 
[132] F. Neugebauer, N. Keller, V. Ploshikhin, F. Feuerhahn, and H. Köhler, "Multi scale FEM simulation for distortion calculation in additive manufacturing of hardening stainless steel," in International Workshop on Thermal Forming and Welding Distortion, Bremen, Germany, 2014.

[133] E. R. Denlinger, J. Irwin, and P. Michaleris, "Thermomechanical modeling of additive manufacturing large parts," Journal of Manufacturing Science and Engineering, vol. 136, p. 061007, 2014.

[134] K. Dai and L. Shaw, "Parametric studies of multi-material laser densification," Materials Science and Engineering: A, vol. 430, pp. 221-229, 8/25/ 2006.

[135] M. F. Zaeh and G. Branner, "Investigations on residual stresses and deformations in selective laser melting," Production Engineering, vol. 4, pp. 35-45, 2010.

[136] F. Neugebauer, N. Keller, H. Xu, C. Kober, and V. Ploshikhin, "Simulation of selective laser melting using process specific layer based meshing," in Proc. Fraunhofer Direct Digital Manufacturing Conf.(DDMC 2014), Axel Demmer, Aachen, Germany, 2014, pp. 297-302.

[137] I. A. Roberts, "Investigation of residual stresses in the laser melting of metal powders in additive layer manufacturing," University of Wolverhampton West Midlands, 2012.

[138] A. Malmelöv, "Modeling of additive manufacturing with reduced computational effort," ed, 2016.

[139] D. Riedlbauer, P. Steinmann, and J. Mergheim, "Thermomechanical finite element simulations of selective electron beam melting processes: performance considerations," Computational Mechanics, vol. 54, pp. 109-122, 2014.

[140] M. J. Berger and J. Oliger, "Adaptive mesh refinement for hyperbolic partial differential equations," Journal of computational Physics, vol. 53, pp. 484-512, 1984.

[141] N. Patil, D. Pal, H. K. Rafi, K. Zeng, A. Moreland, A. Hicks, et al., "A Generalized Feed Forward Dynamic Adaptive Mesh Refinement and Derefinement Finite Element Framework for Metal Laser Sintering-Part I: Formulation and Algorithm Development," Journal of Manufacturing Science and Engineering, vol. 137, p. 041001, 2015.

[142] D. Zhang, Q. Cai, J. Liu, L. Zhang, and R. Li, "Select laser melting of W-Ni-Fe powders: simulation and experimental study," The International Journal of Advanced Manufacturing Technology, vol. 51, pp. 649-658, 2010.

[143] A. Gusarov, I. Yadroitsev, P. Bertrand, and I. Smurov, "Heat transfer modelling and stability analysis of selective laser melting," Applied Surface Science, vol. 254, pp. 975-979, 2007.

[144] K. Dai and L. Shaw, "Thermal and stress modeling of multi-material laser processing," Acta Materialia, vol. 49, pp. 4171-4181, 12/3/ 2001.

[145] A. Vasinonta, J. Beuth, and M. Griffith, "Process maps for controlling residual stress and melt pool size in laser-based SFF processes," in Solid Freeform Fabrication Proceedings, 2000, pp. 200-208.

[146] P. Aggarangsi, J. L. Beuth, and M. Griffith, "Melt pool size and stress control for laser-based deposition near a free edge," in Solid Freeform Fabrication Proceedings, 2003, pp. 196-207. 
[147] A. Simchi and H. Pohl, "Direct laser sintering of iron-graphite powder mixture," Materials Science and Engineering: A, vol. 383, pp. 191-200, 2004.

[148] A. Bejan and A. D. Kraus, Heat transfer handbook vol. 1: John Wiley \& Sons, 2003.

[149] M. Frewin and D. Scott, "Finite element model of pulsed laser welding," WELDING JOURNAL-NEW YORK-, vol. 78, pp. 15-s, 1999.

[150] A. Masmoudi, R. Bolot, and C. Coddet, "Investigation of the laser-powder-atmosphere interaction zone during the selective laser melting process," Journal of Materials Processing Technology, vol. 225, pp. 122-132, 11// 2015.

[151] R. Paul and S. Anand, "Optimal part orientation in Rapid Manufacturing process for achieving geometric tolerances," Journal of Manufacturing Systems, vol. 30, pp. 214-222, $10 / / 2011$.

[152] A. K. Mishra and S. Thirumavalavan, "A Study of Part Orientation in Rapid Prototyping," Middle-East Journal of Scientific Research, vol. 20, pp. 1197-1201, 2014.

[153] A. M. Phatak and S. S. Pande, "Optimum part orientation in Rapid Prototyping using genetic algorithm," Journal of Manufacturing Systems, vol. 31, pp. 395-402, 10// 2012.

[154] M. S. A. Aziz, T. Furumoto, T. Ueda, S. Abe, A. Hosokawa, and R. Tanaka, "Study on thermal and strain behaviour in selective laser sintering process," in Key Engineering Materials vol. 516, ed, 2012, pp. 203-208.

[155] M. Shiomi, K. Osakada, K. Nakamura, T. Yamashita, and F. Abe, "Residual Stress within Metallic Model Made by Selective Laser Melting Process," CIRP Annals - Manufacturing Technology, vol. 53, pp. 195-198, // 2004.

[156] S. Bontha, N. W. Klingbeil, P. A. Kobryn, and H. L. Fraser, "Effects of process variables and size-scale on solidification microstructure in beam-based fabrication of bulky 3D structures," Materials Science and Engineering: A, vol. 513, pp. 311-318, 2009.

[157] I. Yadroitsev, P. Krakhmalev, and I. Yadroitsava, "Selective laser melting of Ti6Al4V alloy for biomedical applications: Temperature monitoring and microstructural evolution," Journal of Alloys and Compounds, vol. 583, pp. 404-409, 2014.

[158] E. Soylemez, J. L. Beuth, and K. Taminger, "Controlling melt pool dimensions over a wide range of material deposition rates in electron beam additive manufacturing," in 21st Annual International Solid Freeform Fabrication Symposium - An Additive Manufacturing Conference, Austin, TX, Aug, 2010, pp. 9-11. 